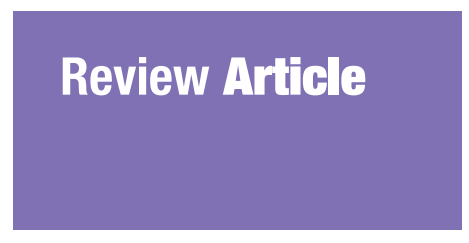

Submitted: 1 Mar 2018 Accepted: 3 Jul 2018 Online: 28 Feb 2019

\section{Determinants of Household Catastrophic Health Expenditure: A Systematic Review}

\author{
Meram Azzani ${ }^{1}$, April Camilla RosLanI ${ }^{2,3}$, Tin Tin Su,
}

1 Community Medicine Department, Faculty of Medicine \& Biomedical Sciences, MAHSA University, Saujana Putra Campus, 42610 Jenjarom, Selangor, Malaysia

2 University of Malaya Cancer Research Institute (UMCRI), Faculty of Medicine, University of Malaya, 50603 Kuala Lumpur, Malaysia

3 Department of Surgery, Faculty of Medicine, University of Malaya, 50603 Kuala Lumpur, Malaysia

4 Centre for Population Health (CePH), Department of Social and Preventive Medicine, Faculty of Medicine, University of Malaya, 50603 Kuala Lumpur, Malaysia

5 South East Asia Community Observatory (SEACO), Jeffrey Cheah School of Medicine and Health Sciences, Monash University Malaysia, 47500 Bandar Sunway, Selangor, Malaysia

To cite this article: Azzani M, Roslani AC, Su TT. Determinants of household catastrophic health expenditure: a systematic review. Malays J Med Sci. 2019;26(1):15-43. https://doi.org/10.21315/mjms2019.26.1.3

To link to this article: https://doi.org/10.21315/mjms2019.26.1.3

\begin{abstract}
The World Health Organization estimates that annually 150 million people experience severe (catastrophic) financial difficulties as a result of healthcare payments. Therefore, a systematic review was carried out to identify the determinants of household catastrophic health expenditure (CHE) in low- to high-income countries around the world. Both electronic and manual searches were conducted. The main outcome of interest was the determinants of CHE due to healthcare payments. Thirty eight studies met the inclusion criteria for review. The analysis revealed that household economic status, incidence of hospitalisation, presence of an elderly or disabled household member in the family, and presence of a family member with a chronic illness were the common significant factors associated with household CHE. The crucial finding of the current study is that socioeconomic inequality plays an important role in the incidence of CHE all over the world, where low-income households are at high risk of financial hardship from healthcare payments. This suggests that healthcare financing policies should be revised in order to narrow the gap in socioeconomic inequality and social safety nets should be implemented and strengthened for people who have a high need for health care.
\end{abstract}

Keywords: catastrophic illness, health expenditure, socioeconomic factors, worldwide, systematic review

\section{Introduction}

A World Health Organization (WHO) report in 2000 noted that one of the principle roles of the healthcare system is to provide equitable financing, which can protect people from experiencing financial hardship incurred due to the treatment of their illness (1). In 2010, a WHO report highlighted that universal health coverage (UHC) would be enable everybody to access health services without facing financial hardship (2). The majority of the population in lowincome countries, and some in middle-income countries, still have to make out-of-pocket (OOP) payments, which is the least sustainable option and an inequitable way of financing health care (3). 
WHO estimates that annually 150 million people experience severe (catastrophic) financial difficulties and about 100 million become poor as a result of healthcare payments (2). Some people who cannot afford the necessary health care engage in alternative coping strategies such as borrowing money, mortgaging or selling assets, selling livestock, and withdrawing their children from school. Some even decide not to seek the health care they need, which may lead to deterioration in health as well as reduced productivity and income (4-8).

Previously, it was generally agreed that if a household spent $10 \%$ or more of its income on healthcare services, the expenditure was classed as catastrophic (9, 10). In 2003, another measurement for catastrophic health expenditure (CHE) was proposed that uses the household's capacity to pay and sets the threshold as equal or more than $40 \%$ of capacity to pay (11). A later study recommended that the capacity to pay should be refined by considering effective income (measured by total expenditure) minus basic subsistence needs adjusted for household size (11).

Several papers have been published on household CHE across the globe. However, different researchers use different measurements of CHE and cut-off points to identify the prevalence of CHE and associated factors. So far, no systematic review has been conducted on these works to identify the key determinants of CHE among households. Therefore, in order to fill this gap in knowledge, a systematic review was carried out to attempt to identify and summarise the significant factors and household characteristics that are associated with the risk of experiencing CHE.

\section{Method}

The Preferred Reporting Items for Systematic Reviews and Meta-Analyses (PRISMA) guidelines were followed in conducting this systematic review.

\section{Search Strategy}

Both electronic and manual searches were performed. Electronic resources included databases and web pages. The databases searched were PubMed, Medline, ScienceDirect, Web of Science, the Cochrane Library, Embase, CINAHLComplet@EBSCOhost and Scopus. Web pages such as Google Scholar were also searched for non-peer reviewed articles in order to reduce the risk of publication bias. In addition, a manual search of the indices of the included studies was done. The papers that were initially selected ranged in date of publication from January 1986 and July 2016 because most of the publications were released from 1986 onwards. The first to study the CHE determinant was from US, he defined a household as having CHE if OOP was equal or more than $10 \%$ of total income (12).

The key words used in the search were catastrophic illness, catastrophic health expenditure, determinants, health expenditure, household factors, financial burden, out of pocket payment and their synonyms.

For a study to be included in this review, the selected study had to define a household as having CHE if OOP was equal to or exceeded $40 \%$ of the household's capacity to pay (11), or had to define it as where OOP was equal or more than $10 \%$ of total income $(9,10)$. The factors associated with CHE that were considered in our review included the household's socioeconomic characteristics, the socio-demographic characteristics of the head of household, the type of illness and treatment and other illness and treatment related factors, and factors such as land ownership.

\section{Selection of Studies and Data Extraction}

The selection of articles/papers was conducted in three steps. All searches were carried out by one reviewer and checked by another. The details of all the selected studies were saved in EndNote X6 software, which was also used to screen for duplicate studies. In the first step, the articles were independently selected by two reviewers based on the title and abstract after excluding the duplicate articles in the list. Disagreement on article selection between reviewers was resolved by consensus and consultation with a third reviewer. A total of 3,188 articles were identified, of which 382 were removed because of duplication. Then, we reviewed the titles and abstracts and excluded studies if they reported on CHE without including its determinants or if they reported on the economic burden of households but did not measure CHE. Papers not written in the English language, qualitative studies, case studies, and studies on specific health problems, on specific age group (elderly) and on macrolevel comparisons were also excluded. At this point, 67 papers were eligible for full document review. After evaluating the documents in full, 27 more papers were removed because the CHE 
Review Article | Determinants of catastrophic health expenditure

only focused on a specific health problem or purchased medication. Out of the remaining 40 studies, 38 were finally selected for this systematic review after quality assessment (Figure 1).

\section{Quality Assessment}

The quality of the initially selected studies was assessed by using the critical appraisal checklist for survey-based studies (13), which comprises the following questions:

1. Did the study address a clearly focused issues/question?

2. Is the research method (study design) appropriate for answering the research question?

3. Is the method of selection of the subjects (employees, teams, divisions, organisations) clearly described?

4. Could the way the sample was obtained introduce (selection) bias?

5. Was the sample of subjects representative with regard to the population to which the findings will be referred?

6. Was the sample size based on pre-study considerations of statistical power?

7. Was a satisfactory response rate achieved?

8. Are the measurements (questionnaires) likely to be valid and reliable?

9. Was the statistical significance assessed?

10. Are confidence intervals given for the main results?

11. Could there be confounding factors that haven't been accounted for?

12. Can the results be applied to your organisation?

Total identified articles $(3,188)$

Removal of duplicates

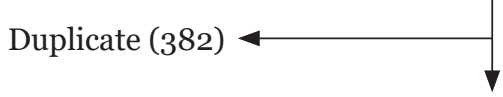

Primary relevant assessment $(2,806)$

Non relevant (depends on title and abstract) (2,739)

- Non English

- Qualitative articles

- Case study

- CHE without its determinants

- CHE at macro-level comparison

Non - relevant articles (27)

- CHE for specific health problem or Specific age group (elderly)

- CHE and burden for medicines only

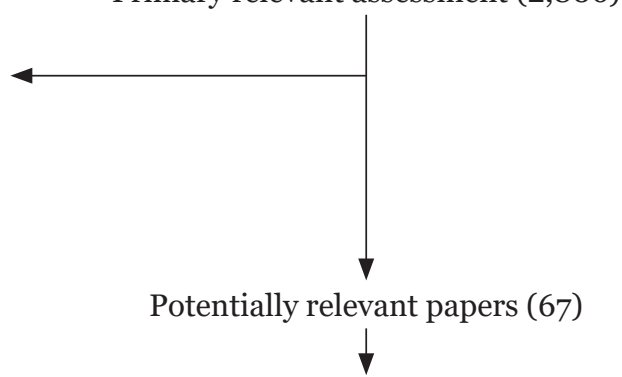

Relevant assessment of full document version (67)

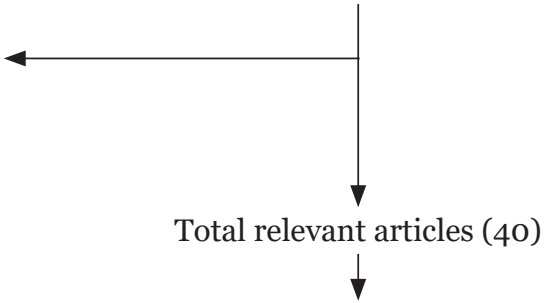

Quality assessment of relevant articles (40)

Low quality articles (2)

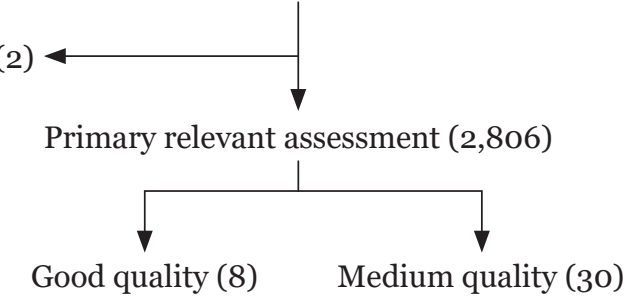

Figure 1. Identification of studies 
Each criterion was scaled as either reported or not reported. Each question is scored 1 if reported and o if not reported. Two reviewers scored the papers independently; the third was involved in arbitration if a disagreement occurred. The final selection was done based on the result of this quality assessment. Only studies of good (7-12 points) or medium (4-6 points) quality were included in this systematic review. Two studies got less than 4 points score, for that, they were considered as low quality and we didn't include them in this review. The results of the quality assessment are shown in Table 1.

Table 1 provides details of the studies that were selected for review including year of publication, country under study, study design, sample size, outcome measures, method of analysis, results and conclusion.

\section{Results}

\section{Description of Studies}

The final set of 44 selected papers (eight high quality and 30 medium quality) were grouped by country under study into low, middle and high income according to the World Bank classification (14). Thus, four papers investigated $\mathrm{CHE}$ in high-income countries (USA, the Czech Republic, South Korea and Portugal), 31 examined the issue in middle-income countries (one each on Colombia, Georgia, Vietnam, Serbia, Bangladesh, West Bank and Gaza (Palestine), Zambia, two on Myanmar, two on Brazil, two on Kenya, three on Iran, three on Turkey, two on Thailand, three on India and seven on China) and three presented research on CHE in low-income countries (Uganda, Burkina Faso and Tanzania) (see Table 2).

\section{Determinants of Catastrophic Health Expenditure}

Table 2 shows the determinants of CHE according to the income level of the country.

\section{Household}

\section{a. Residence}

Eighteen studies examined household residence as one of the potential determinants of $\mathrm{CHE}(15-32)$. Six studies found that this variable is not significant (15, $18,19,23,30,31$ ), but most of the studies found that living in a rural area is a risk factor for incurring $\mathrm{CHE}(16,17,20-22$,
24-29). Conversely, one study found that living in a rural area is a protective factor for incurring CHE (32).

b. Family size

A total of 25 studies investigated the relationship between family size and incurring $\mathrm{CHE}(15,16,18-22,24-28,31-$ 43). Five studies found that the relationship is not significant $(16,19,36,38,41)$, ten studies found that a large family size is a risk factor $(18,20,22,24,26,31,32,34,35$, 40) and ten found that a small family size is associated with a higher risk $(15,21,25,27$, $28,33,37,39,42,43)$.

c. Presence of an elderly person in family

The presence of an elderly person in the household was found to be significant as a risk factor for $\mathrm{CHE}$ in all 19 papers that evaluated this variable in their analyses (15$17,19,21,22,25-28,32-34,36,39,41-44)$.

d. Presence of children aged under 5 years old

Of the 16 papers that studied this factor, six found that the presence of children aged under 5 years old is not a significant factor in determining $\mathrm{CHE}(19,36,41,42,44$, 45), while three studies reported that it is a protective factor $(16,21,23)$. The other seven studies found that the presence of children under 5 years old is a risk factor for CHE (22, 25, 26, 28, 32, 34, 39).

e. Economic status

Of the 33 studies that considered the economic status of the household $(12,15,16$, 18-30, 32, 33, 35-37, 39, 41-51), 28 found that households in the lowest expenditure quintile or quartile or lowest income are at higher risk of experiencing CHE. However, five studies reported that households in the highest expenditure quintile/tertile spend more on health care at a level exceeding the capacity to pay threshold $(19,25,26,28,45)$. The majority of studies expressed economic status in terms of expenditure quintiles (15, 16, 19-22, 24, 25, 30, 35-39, 42, 44, 47-51); however, one of the studies used expenditure quartiles (18) and one of the studies used expenditure tertiles (45). In addition, five studies used income as a continuous variable to express the economic status of the household (12, 23, 27, 29, 33). 
Review Article | Determinants of catastrophic health expenditure

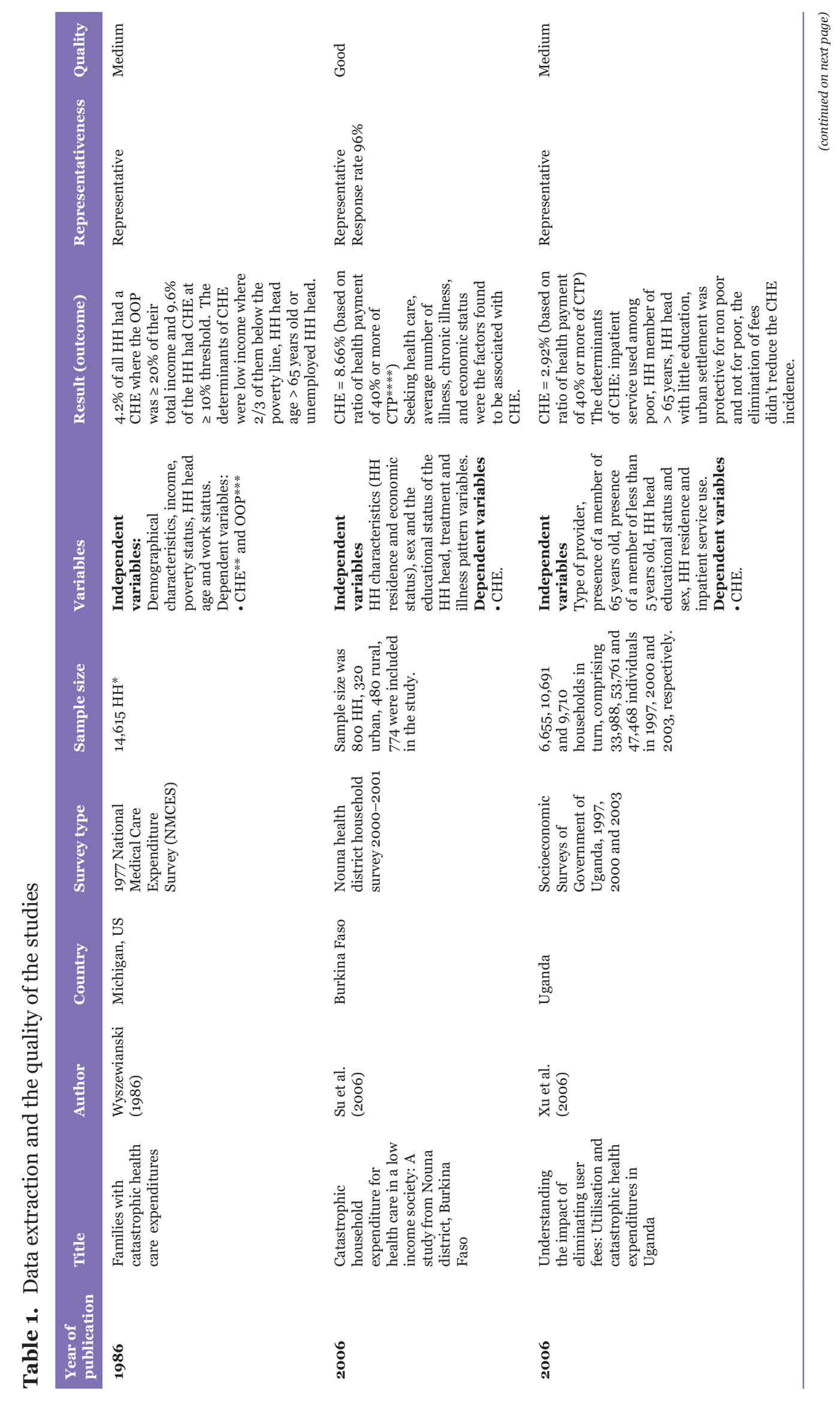



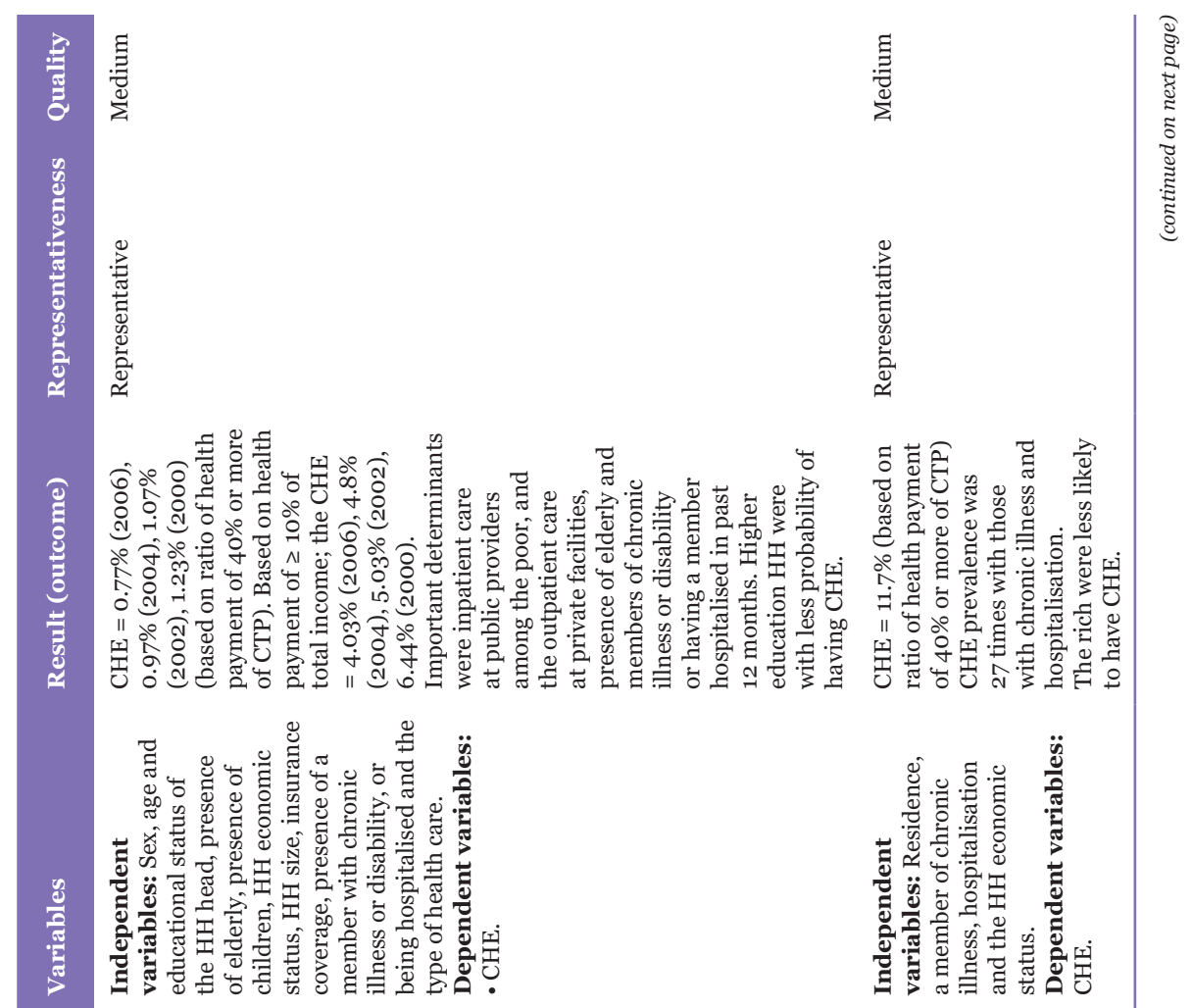

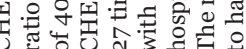
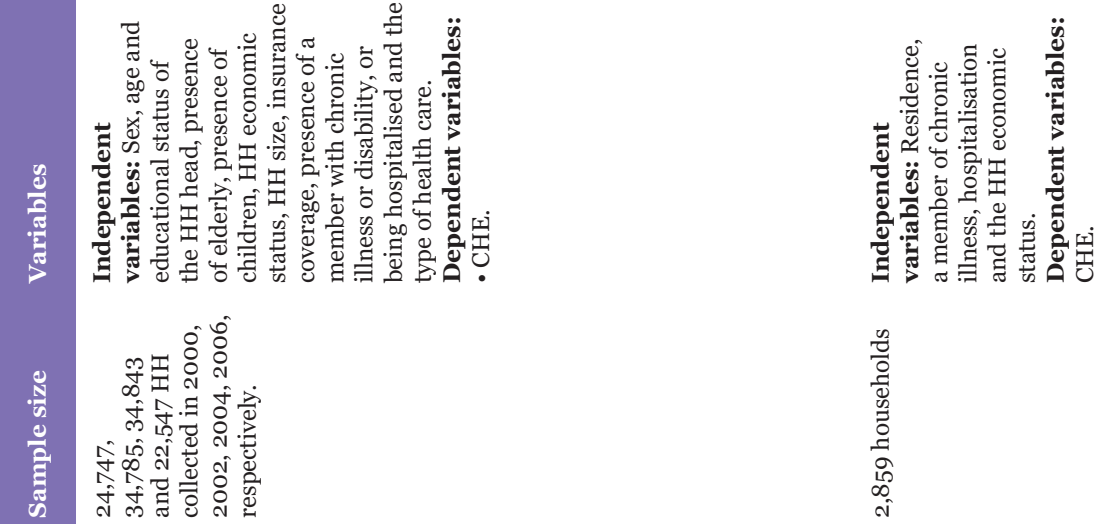

0
0
0
0
0
0
0
0
0
0
i
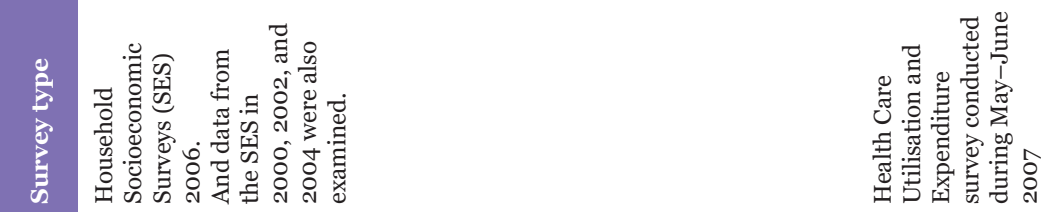

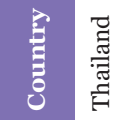

䓵

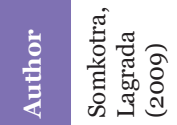

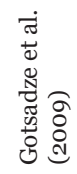
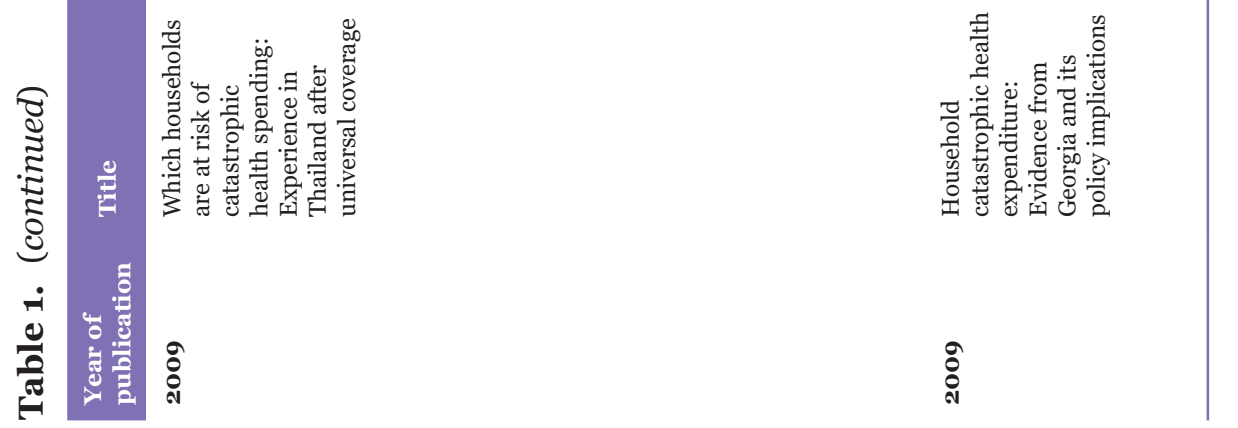
Review Article | Determinants of catastrophic health expenditure

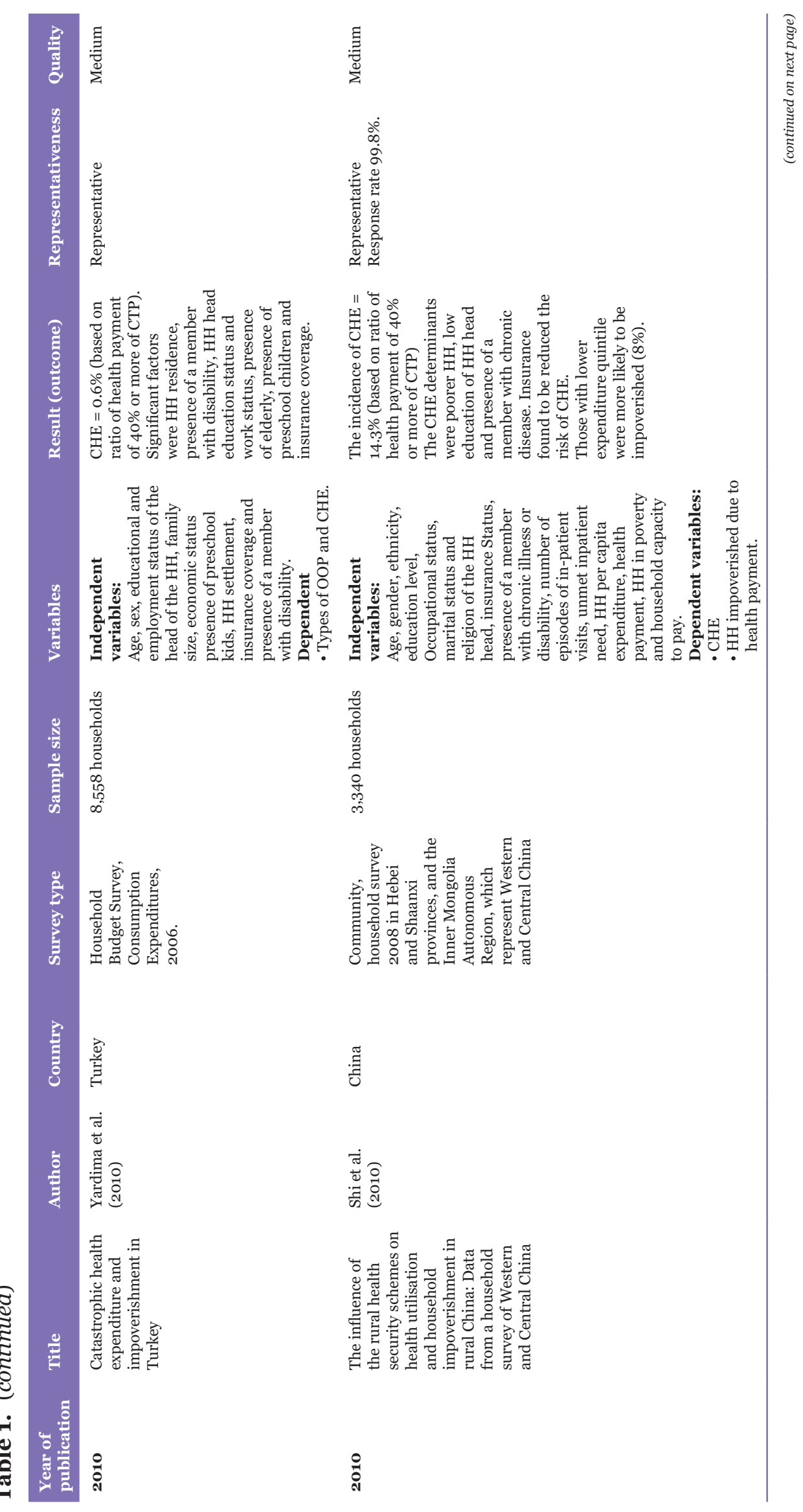




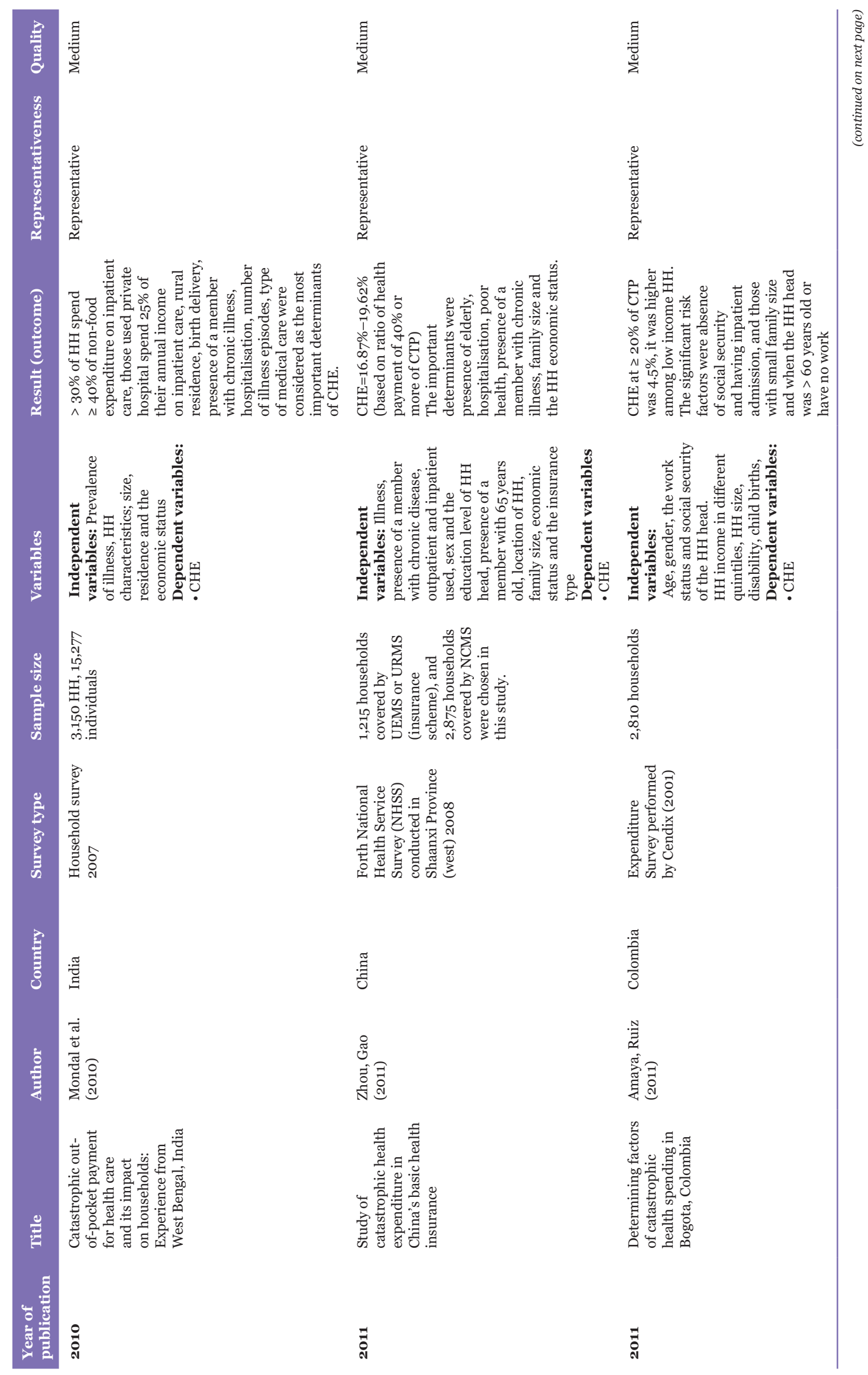


Review Article | Determinants of catastrophic health expenditure

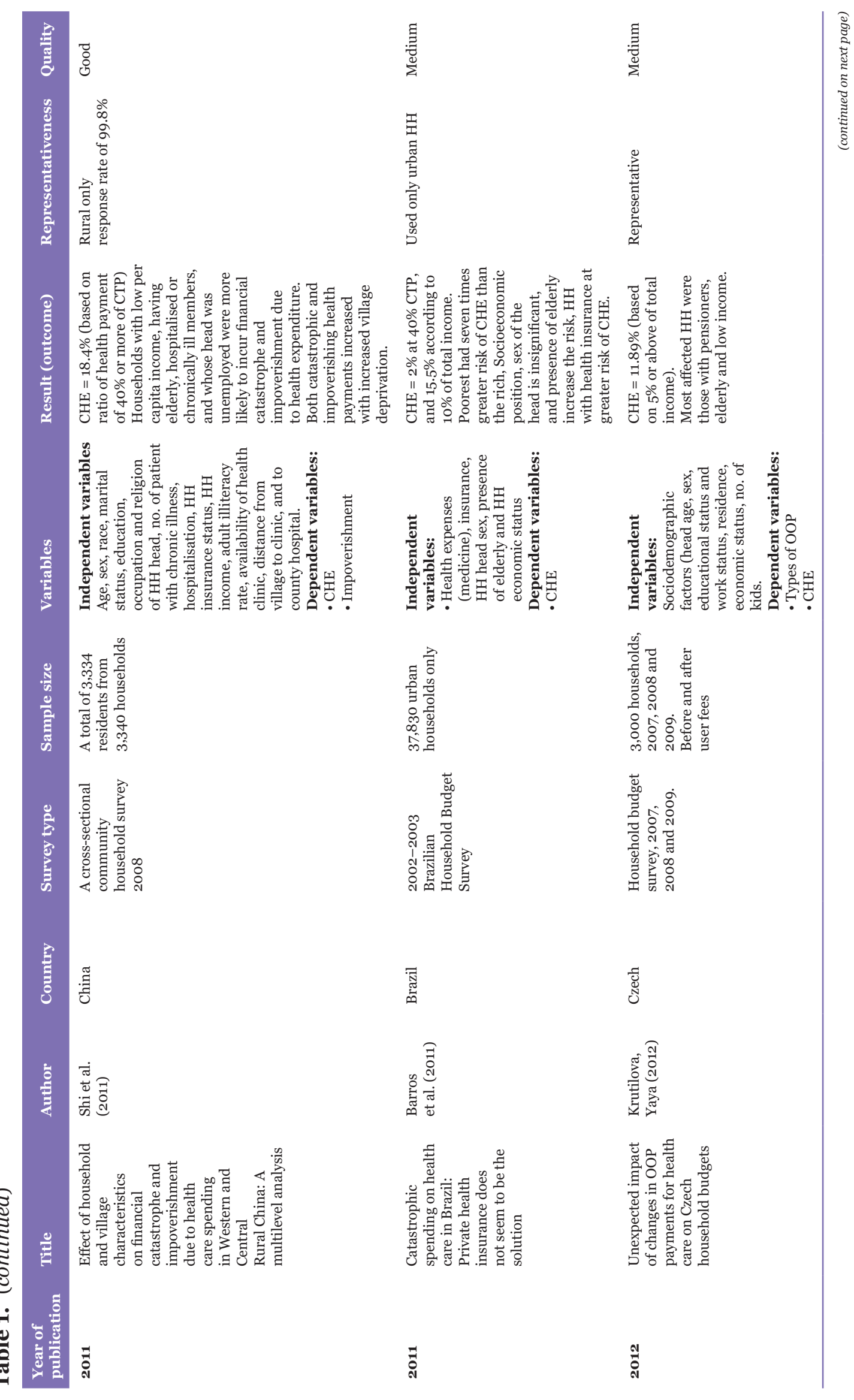



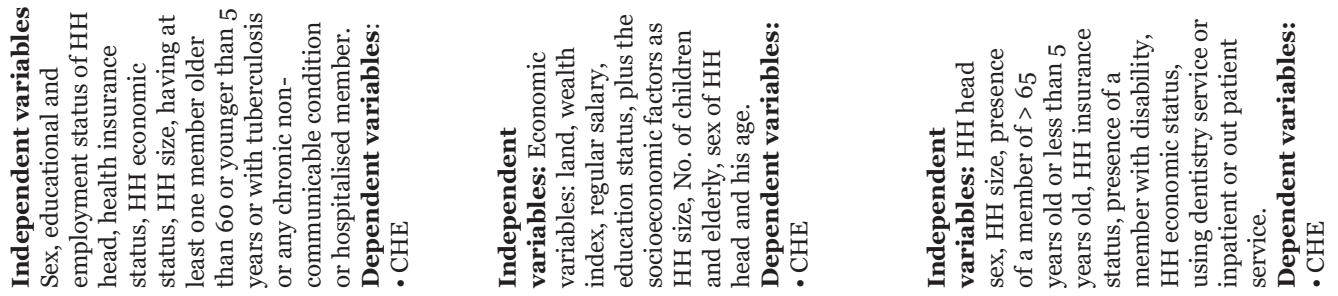

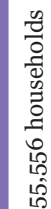

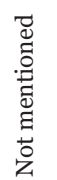

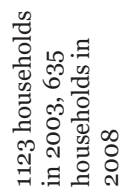

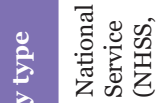

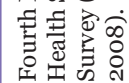

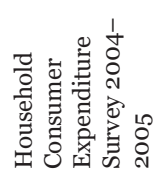

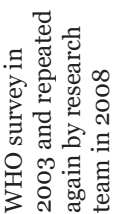

竞

愛

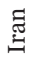

बूँ

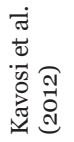

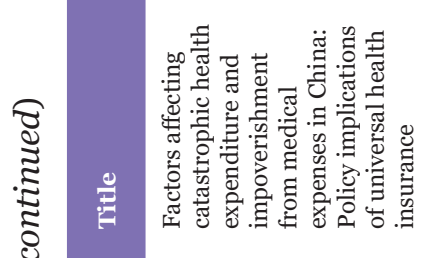
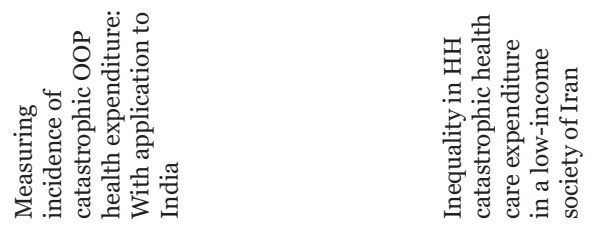
Review Article | Determinants of catastrophic health expenditure

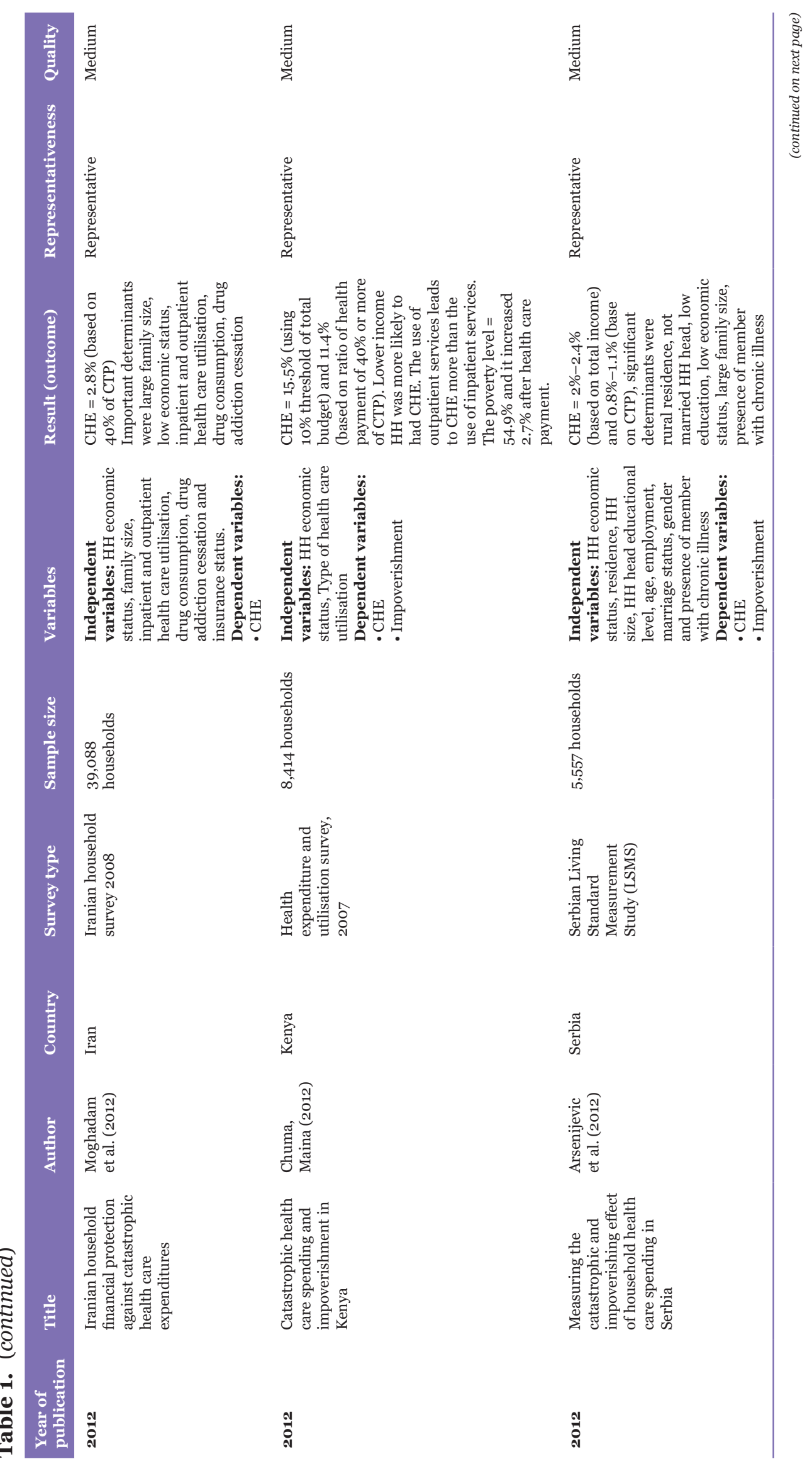



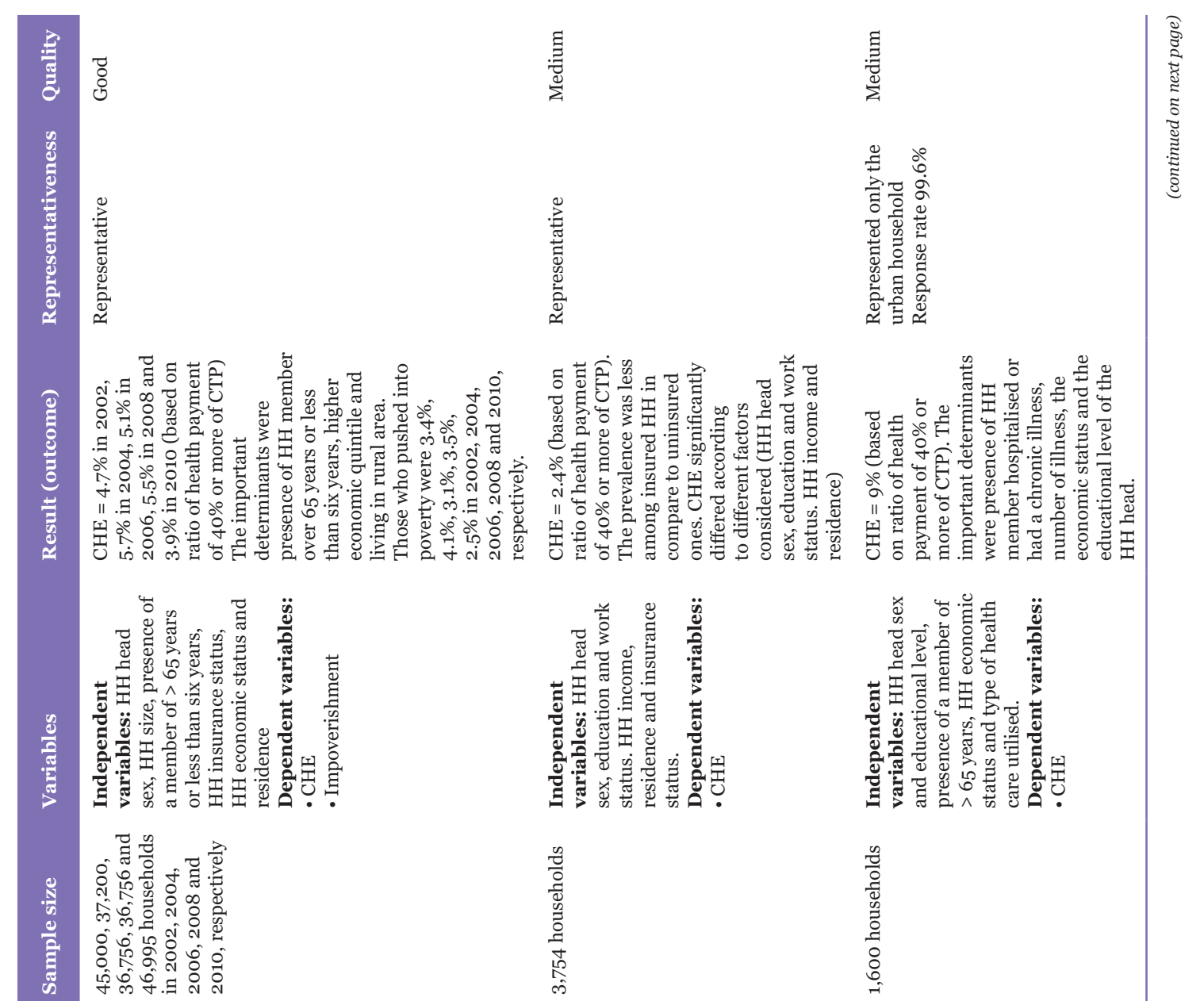

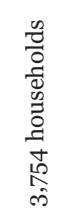
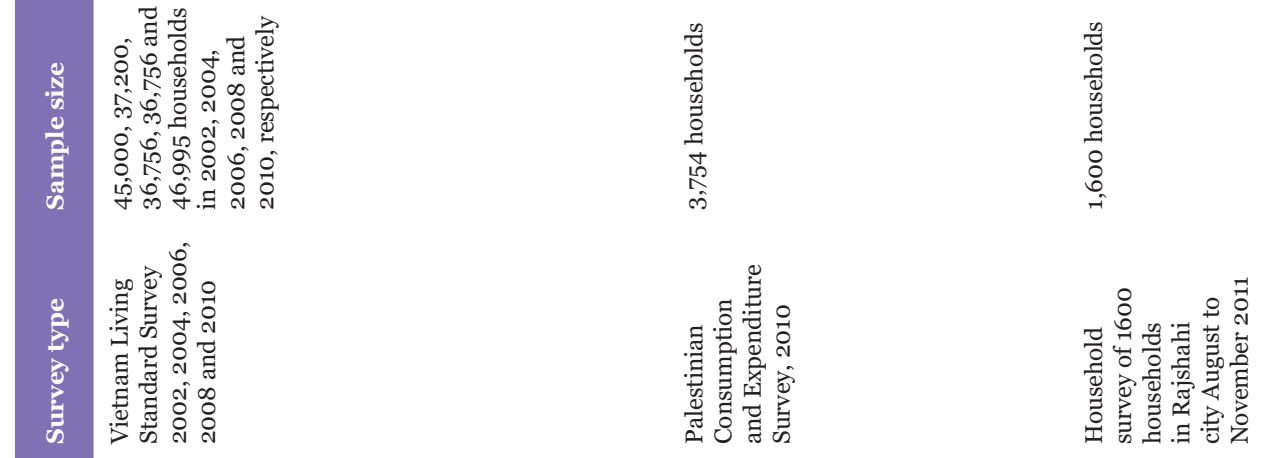

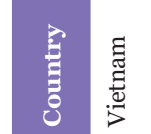
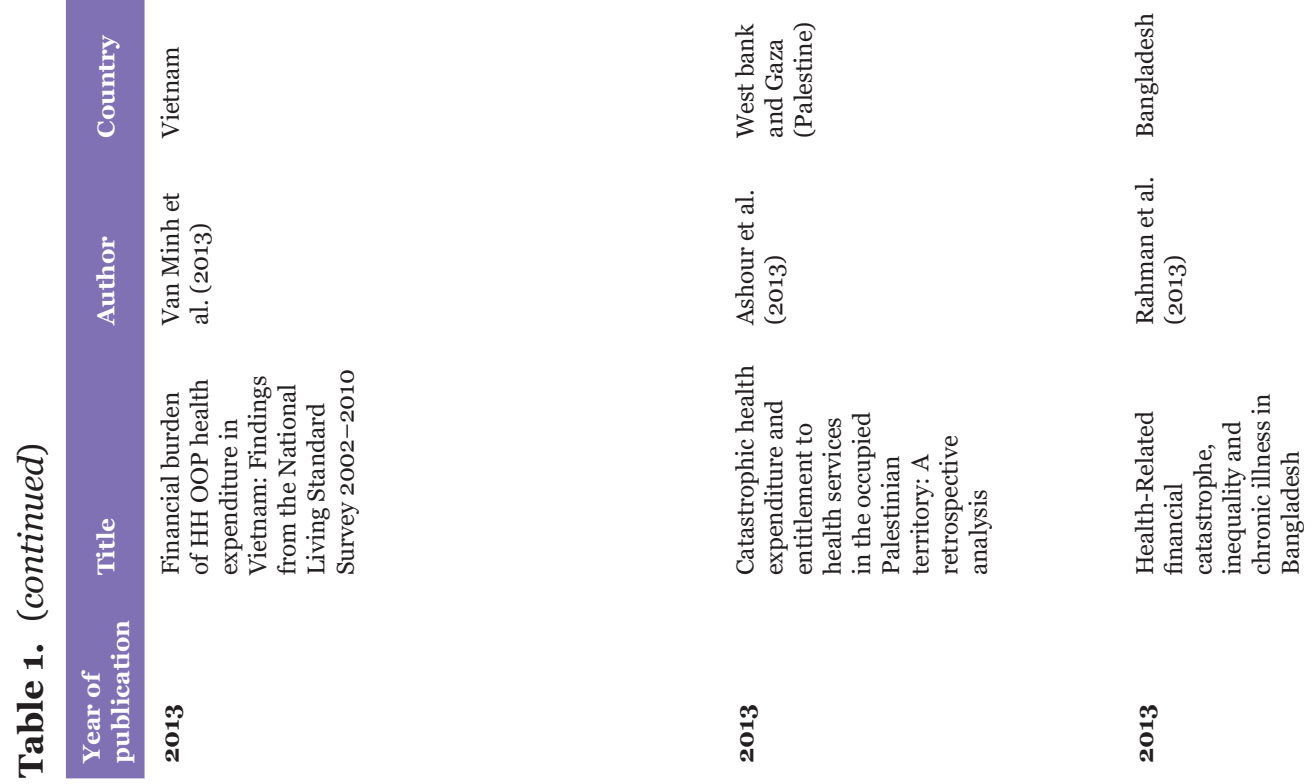
Review Article | Determinants of catastrophic health expenditure

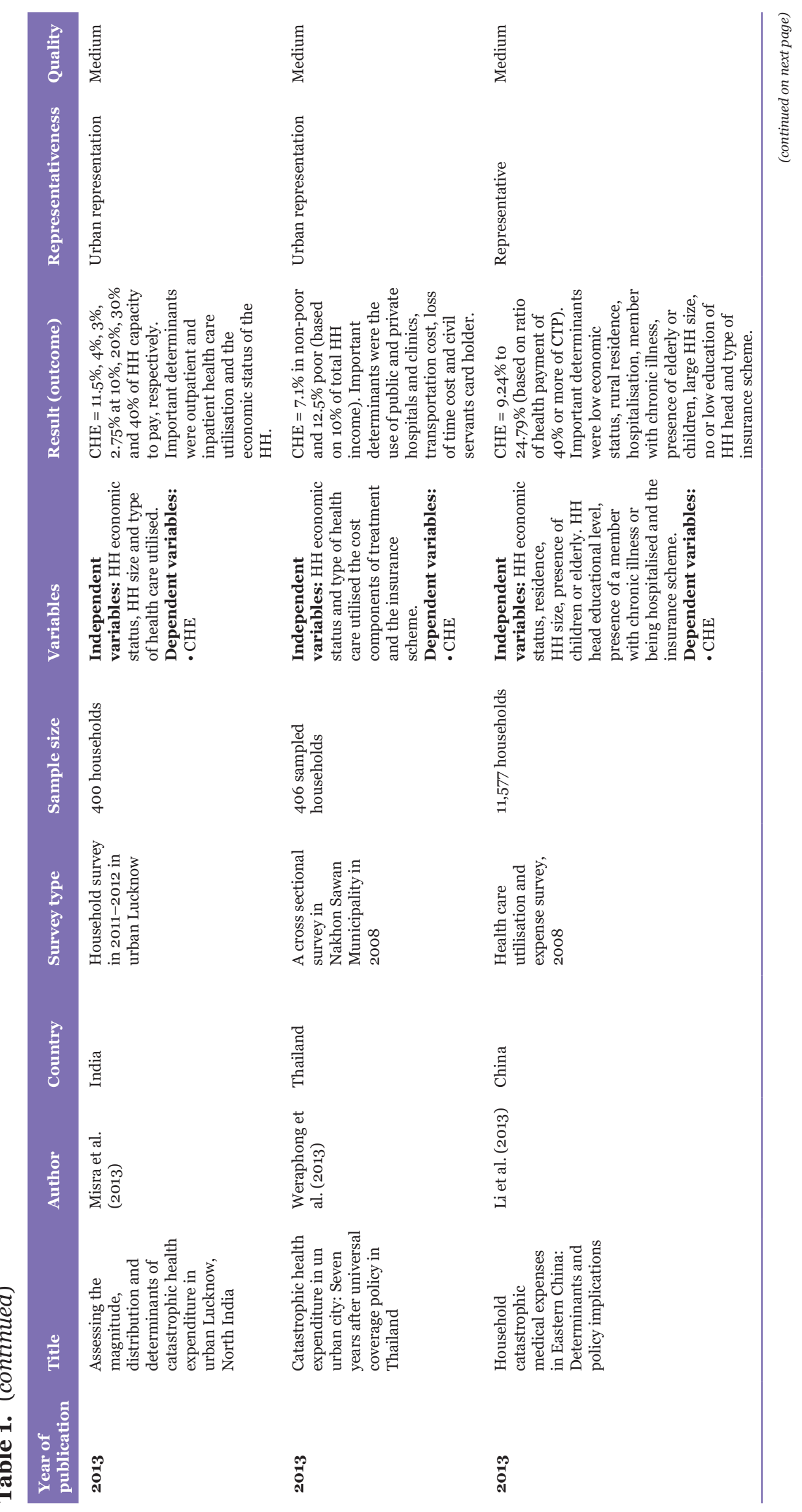



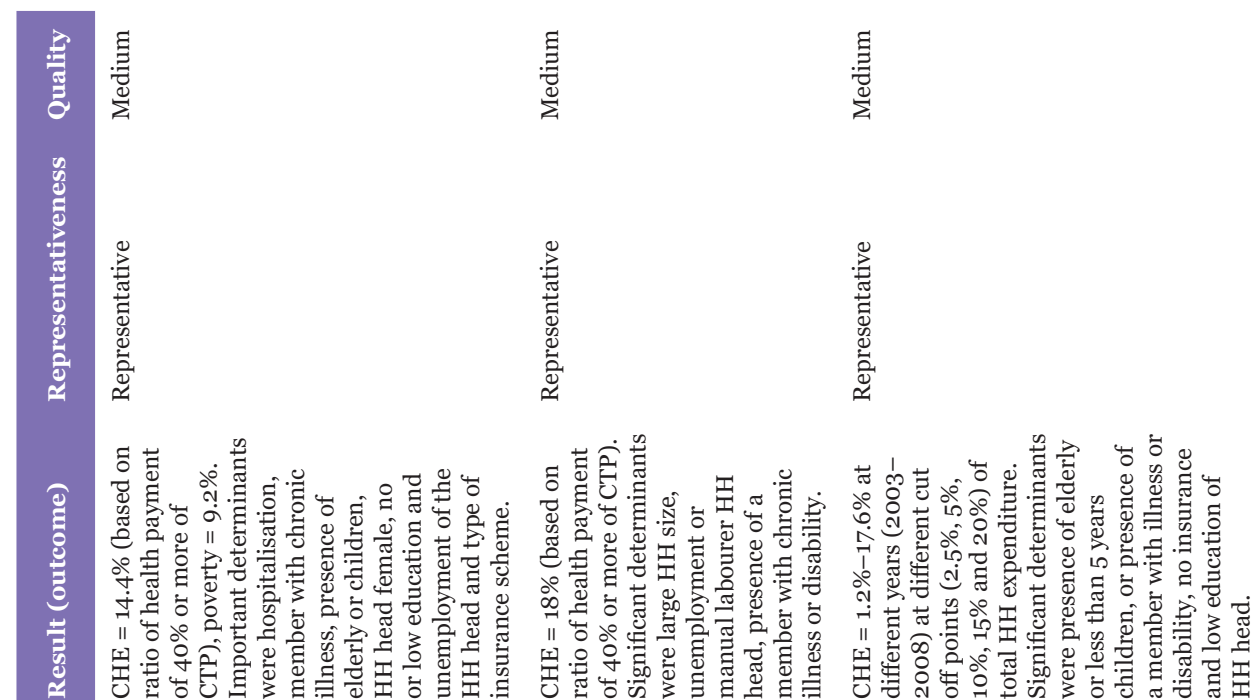
II

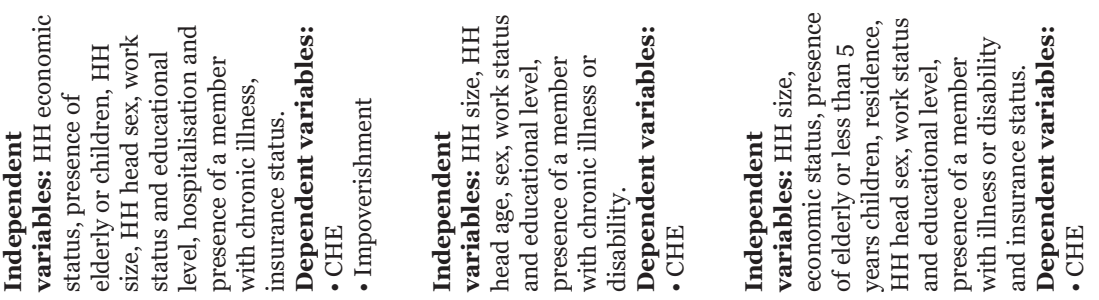

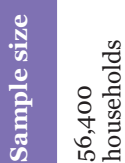
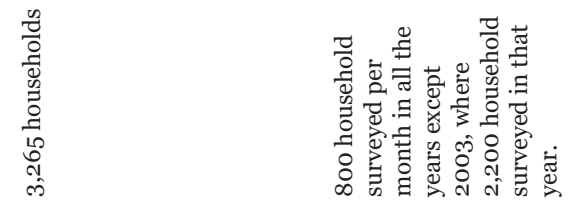

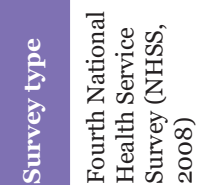
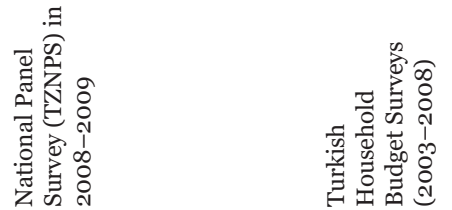

हैं

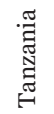

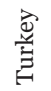

菊离

$\frac{\pi}{\pi}$

营莡

离
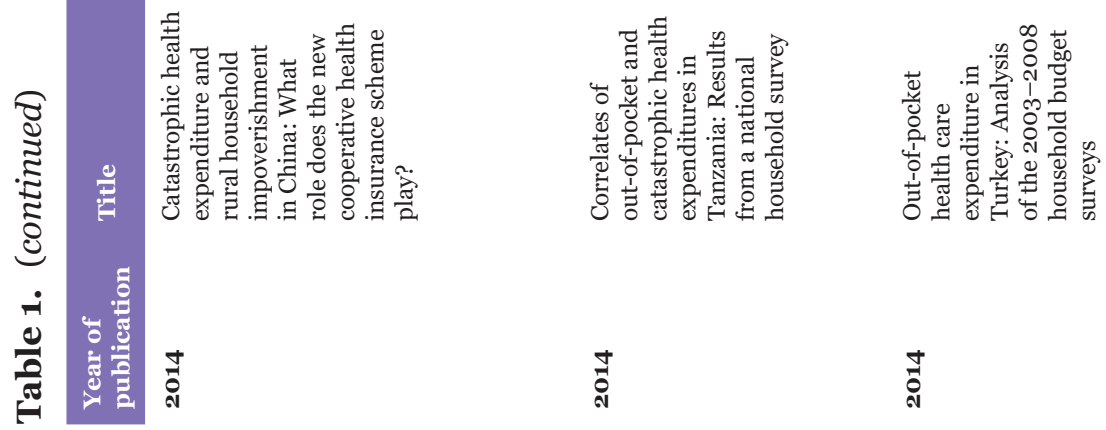
Review Article | Determinants of catastrophic health expenditure

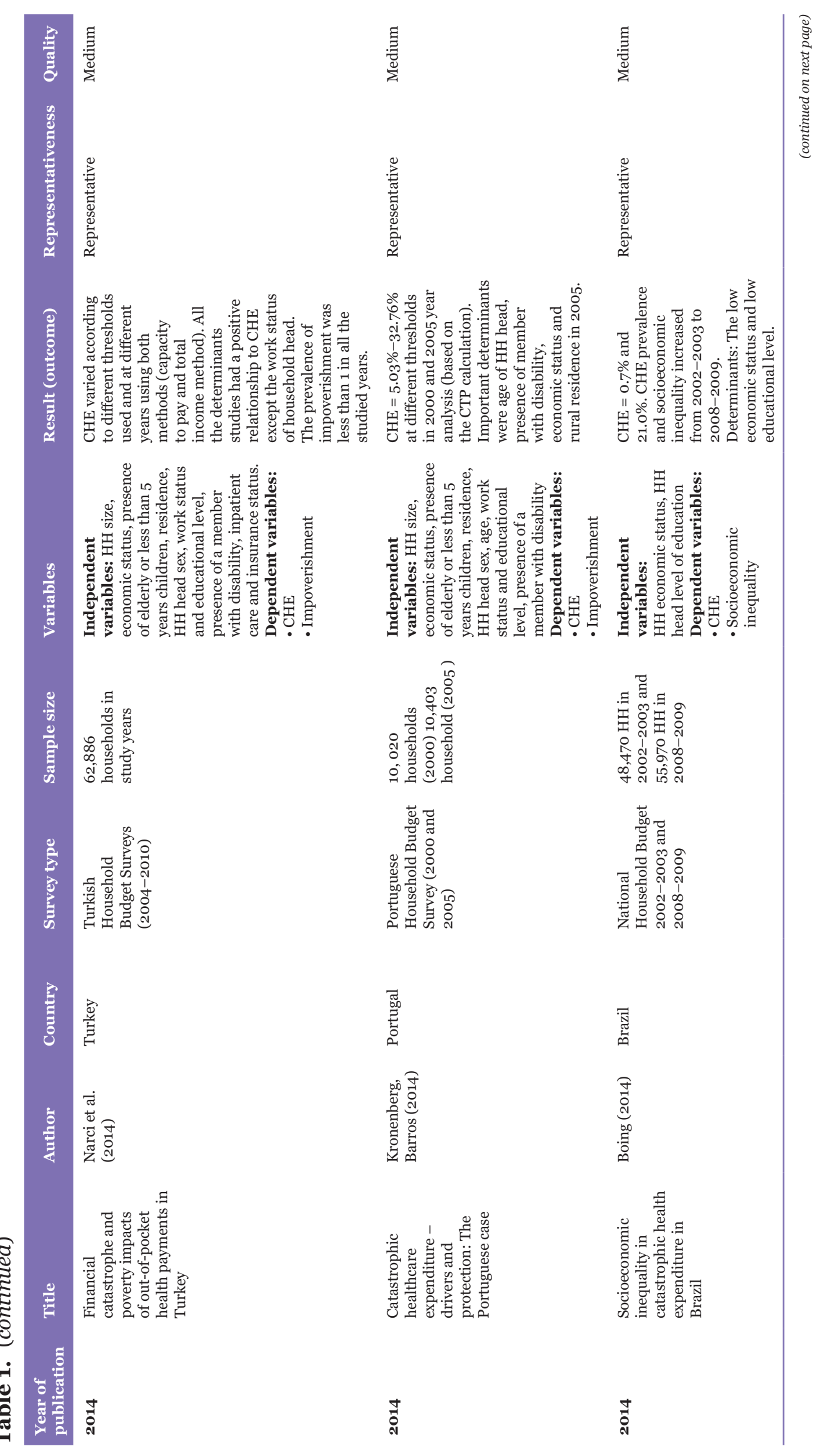




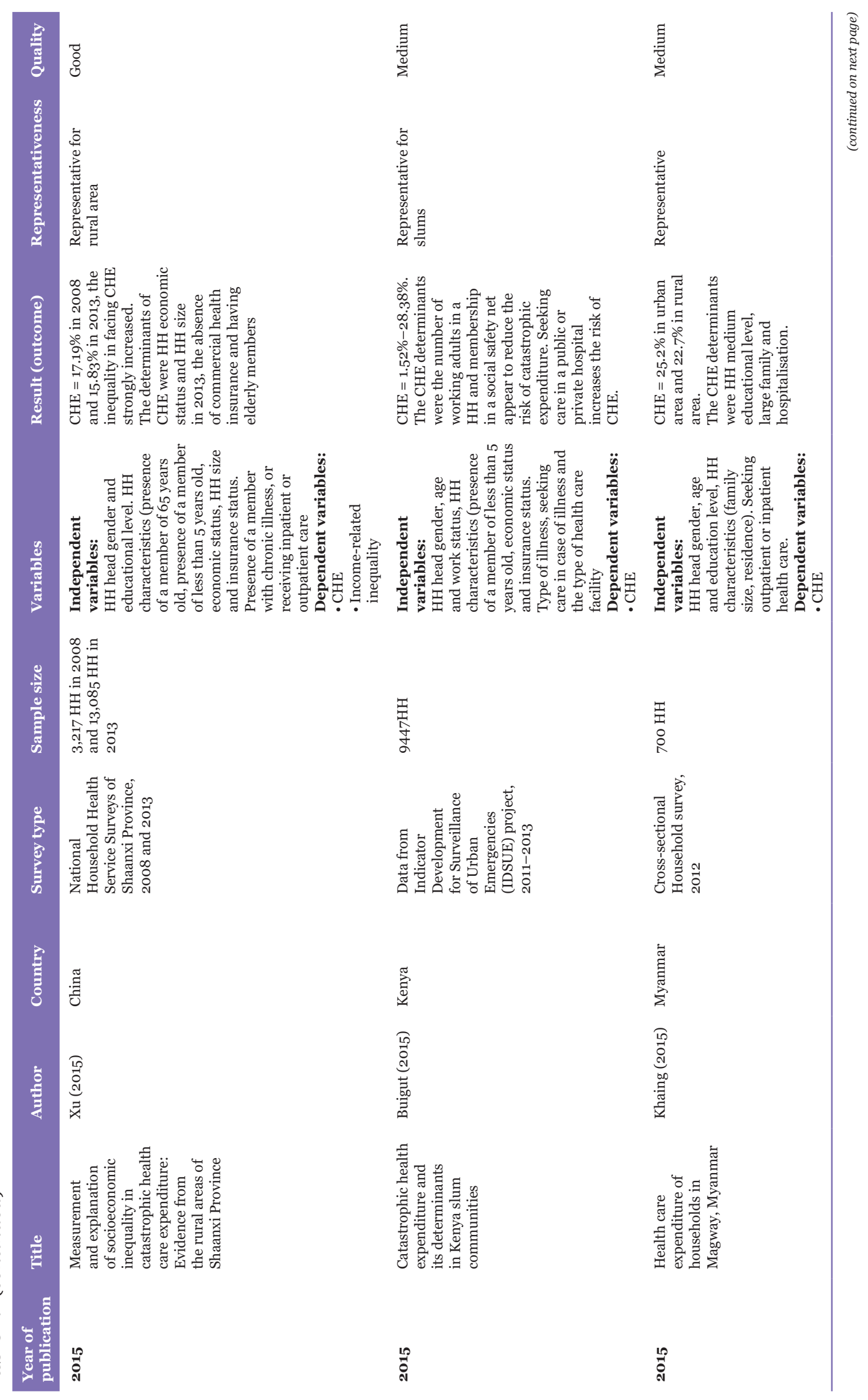


Review Article | Determinants of catastrophic health expenditure

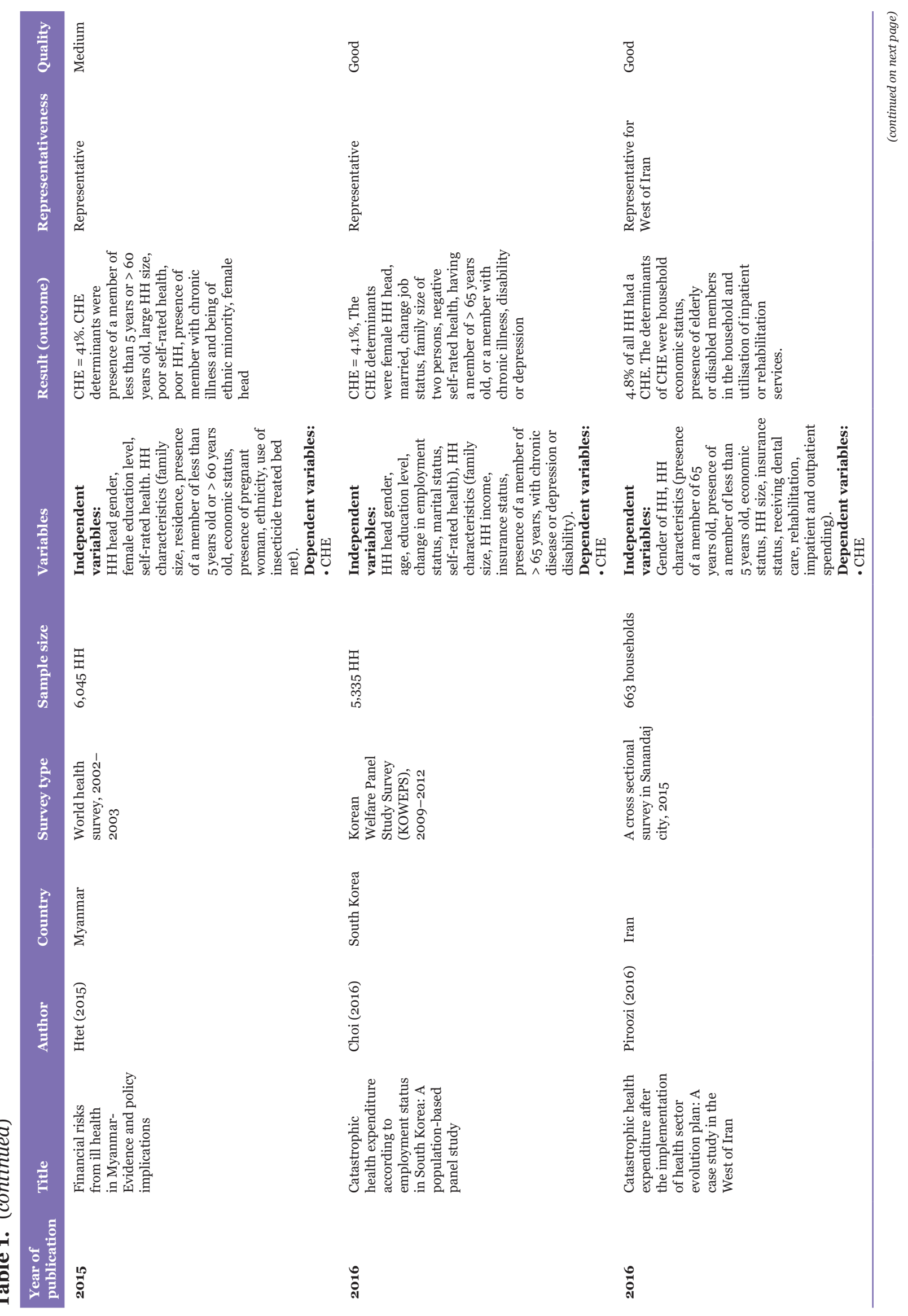




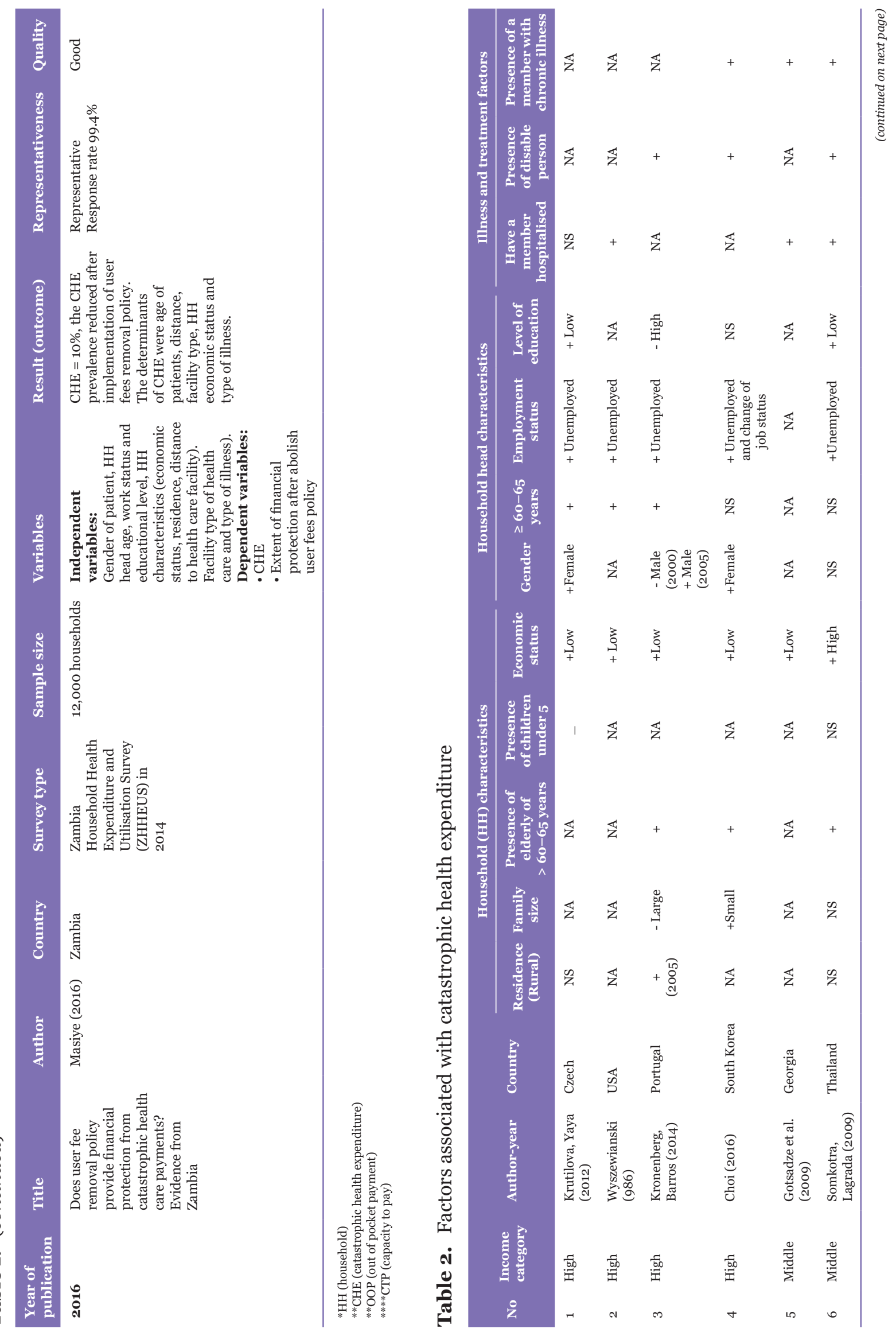


Review Article | Determinants of catastrophic health expenditure

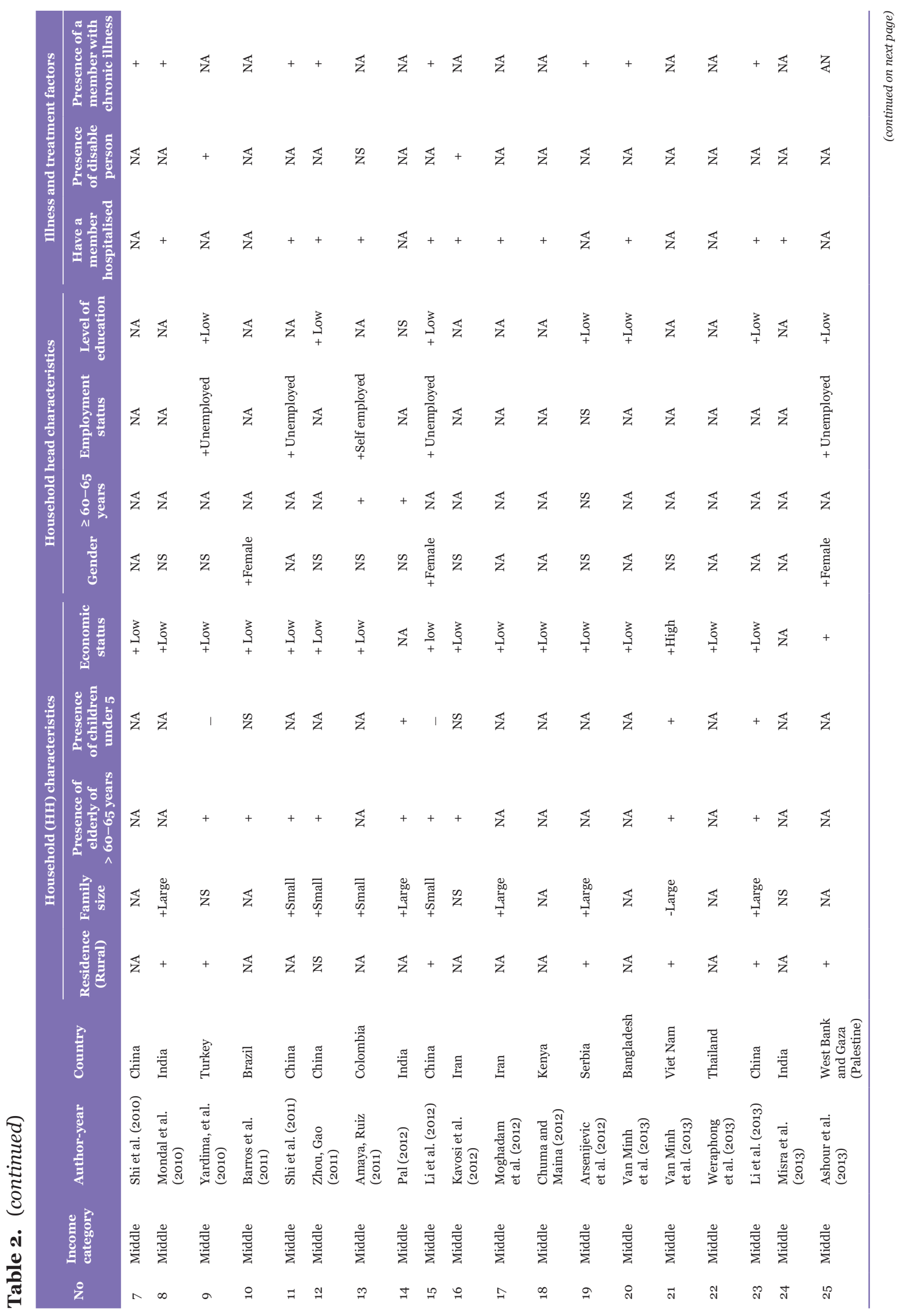


Malays J Med Sci. Jan-Feb 2019; 26(1): 15-43

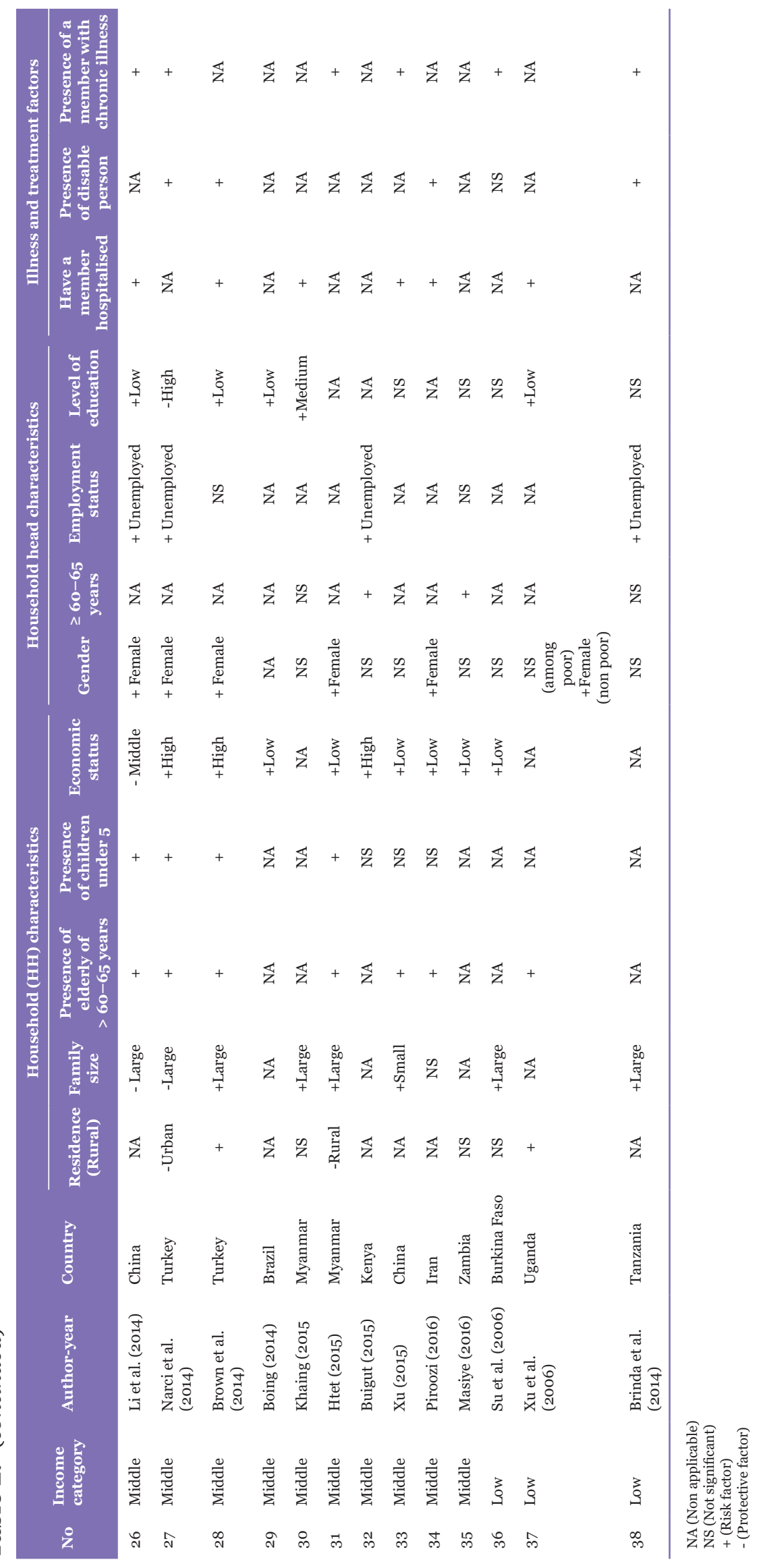


Review Article | Determinants of catastrophic health expenditure

\section{Head of household}

\section{a. Gender}

The gender of the head of household was found to be a non-significant factor in 16 papers out of the 27 that analysed this factor $(15,16,18-20,24,25,30-32,34,36$, $37,40,42,45)$. However, in the remaining 11 studies, a female head of household is identified as a risk factor $(17,21,23,26-29$, $39,41,43,44)$. In Uganda, this variable was found to be a risk factor among the nonpoor, but not significant among the poor (17). In Portugal, it was found to be a risk factor in the year 2005 but a protective factor in the year 2000 (27).

\section{b. Age}

The influence of the age of the head of household was analysed in 12 studies. Five studies found that the age of the head of household is not significant $(19,24,31,40$, 43), whereas seven found that this factor is a significant determinant of CHE, where the older the age of the head of household the greater the risk of experiencing a financial catastrophe (12, 23, 27, 30, 34, 37, 45).

\section{c. Employment status}

Of the 17 papers that analysed the employment status of the head of household, 11 found that an unemployed head of household is a risk factor for CHE $(12,16$, $19-21,27-29,33,39,40$ ), while one study done in Colombia reported that being selfemployed and a government worker are also risk factors for incurring CHE (37). Another study done in Kenya reported that being self-employed and a government worker are protective factors for incurring CHE (45). One study done in South Korea reported that people who experienced changes in job status from employed to unemployed or were unemployed with no status change were more likely to incur CHE (43).Three studies found this variable is not significant $(24,26$, 30) for CHE.

\section{d. Educational status}

A total of 22 articles considered educational status as a factor in CHE (15-19, 21-24, $26-31,34,39,40,42,43,50,51)$. Six found this factor to be insignificant $(18,30,34$, $40,42,43$ ), while 15 papers reported that low education is related to the increased probability of experiencing CHE. The remaining one paper reported that medium education is related to increase the probability of experiencing CHE (31).

\section{Illness and treatment}

a. Hospitalisation (inpatient care)

Twenty one studies investigated hospitalisation as a possible determinant of CHE (12, 15-17, 19-22, 26, 31, 33, 35-39, 41, $42,48-50)$. Hospitalisation was found to be a significant positive predictor of CHE in all but one of the 21 studies.

b. Presence of a disabled person

Of the eleven studies that examined disability as one of the predictors of CHE (16, $18,19,26-8,36,37,40,41,43)$, two reported a non-significant relationship (18, 37), while the remaining nine reported a significant association that increases the risk of CHE.

c. Presence of a family member with a chronic illness

The presence of a family member with a chronic illness was found to be a significant factor for CHE in all 17 studies that analysed this factor $(15,18-20,22,24,28,32,33$, $39-43,47,48,50)$.

d. Other illness and treatment related factors

Several studies identified some additional CHE determinants, which are (in no particular order of preference) as follows: Healthcare utilisation in general was found to be a risk factor in studies conducted in Burkina Faso (18), Iran (36), India (38) and Kenya (49). The number of illness episodes was identified as a risk factor for CHE in India (20). Drug consumption was a risk factor in a study done in Iran (35). Perceived health status was identified as a risk factor for incurring CHE in Serbia (24). Having a communicable disease, such as tuberculosis, was found to be a risk factor in China (39). Finally, seeking dental care and rehabilitation services were found to be positive predictors of CHE in Iran (41), and seeking health care from a traditional healer were also found to be positive predictors of CHE in Tanzania (40). Utilisation of outpatient health care was risk factor in rural area of China (42) and it was not significant factor in Myanmar (31). 


\section{Other factors}

Lastly, in one study on India, land ownership and a higher level of education for the female heads of household in rural areas are considered to be protective factors that could reduce CHE (34). In Zambia, distance from health care facility, type of illness and type of health care facility were considered to be factors that could affect the CHE, too (30). However, other factors as number of working adults, type of illness and duration stay in slum area, seeking care from public or private hospital were considered by study done in Kenya (45). Study done in South Korea explored other factors and found that, having a member with depression and being married are also risk factors of CHE, however household with negatives self-rated health and household that benefits from medial aid programme are less likely to incur CHE (43). In Myanmar, the researchers explored other factors as ethnic status, household with pregnant women, the number of educated females, the use of insecticide treated bed nets and selfrated health, and they found only the latter was significant (32).

\section{Prevalence of Catastrophic Health Expenditure}

Four studies, two on high-income countries and two on middle-income countries based the calculation of CHE solely on total income. On the other hand, 27 studies measured CHE based solely on capacity to pay.

Only seven studies used both methods of calculation (total income and capacity to pay) and compared the result on the prevalence of CHE derived from the two different methods. Six of these studies were conducted on middleincome countries and one investigated a lowincome country.

Thus a total of 11 studies used total income to calculate CHE (12, 19, 23, 24, 26, 28, 30, 34, 44, 46, 49). Six studies used a cut-off point ranging from $5 \%$ to $20 \%$ of total income $(12,23$, $24,26,28,44)$, while five used a cut-off point, i.e. $10 \%$ of total income. It is difficult to compare the results on the prevalence of CHE reported in these studies not only due to the different cut-off points used in the CHE calculation, but also due to the wide time frame (1986-2016) covered by the included studies.

A total of 34 studies used capacity to pay to calculate CHE. Ten used a cut-off point ranging from $10 \%$ to $60 \%$, which again makes it difficult to make a comparison across studies. The other
24 studies used only one cut-off point to calculate CHE.

The seven studies that applied capacity to pay as well as total income to calculate CHE $(19,24,26,30,34,44,49)$ found that $\mathrm{CHE}$ prevalence estimated by total income is higher than when estimated by household capacity to pay.

\section{Role of Insurance in the Occurrence of CHE}

The role of insurance was examined in 17 studies $\left(15,16,21,22,25,26,28,29,33,35^{-}\right.$ $37,39,43,44,46,47$ ) (Table 3). Nine studies found that insurance schemes helped to reduce the risk of incurring $\mathrm{CHE}(16,21,25,26,28$, $29,36,37,47)$. On the other hand, two studies found that having insurance was a risk factor for incurring CHE $(33,44)$. Four studies reported that insurance does not have a significant effect on the occurrence of CHE $(33,35,43,46)$. Two of the studies on the situation in China both reported that the role of insurance depends on the type of insurance scheme that the household has; urban health insurance was found to be protective whereas rural health insurance was found to be a positive predictor that increases the risk of experiencing $\mathrm{CHE}(22,39)$.

\section{Discussion}

This systematic review found that irrespective of the economic status of the country under study the determinants of CHE were broadly similar. For instance, people living in a rural area and belonging to the lower income quintiles were more likely to experience CHE compared to urban residents and richer people $(15,16,18,20,21,33,34,37,44,47,48)$. However, definition of rural area from country to country may differ. Therefore the role of living area on CHE may vary. Moreover, in most cases there is a strong relation between rural area and large family size. Therefore living area sometimes may be a confounding factor. In general, socioeconomic status was one of the significant indicators of CHE across countries (52).

The low educational level of the head of household was also found to be significant in determining CHE in several studies $\left(15^{-17}, 19\right.$, 21-24, 26-29, 39, 50). Generally, educated people have a greater awareness about health and tend to be more frequent users of preventive services and health care. In addition, they are more likely and able to maintain a regular job 
and cope with financial expenses, including those for health care. Employment status was also found to be significant in many studies (12, 16, 19-21, 27-29, 33, 39, 40) that found heads of household who are not working or are self-employed are at a greater risk of incurring CHE as they have no regular income. This was supported by another finding identified in this review, namely that households headed by a woman had a higher probability of CHE in high- and middle-income countries (17, 23, 44). However, the gender of the head of household was not identified as a significant factor in the studies on low-income countries. This may be due to the fact that in low-income countries women are usually less educated and not able to ensure a sustainable income. The importance of the education of women head of household in the reduction in the likelihood of CHE is also highlighted in the study conducted in India (20).

The results for the influence of other household and head of household characteristics are varied depending on country and therefore general conclusions cannot be drawn from them. Nevertheless, it can be said that, apart from the above three indicators of socioeconomic inequality (income, education and employment status), hospitalisation, presence of an elderly person, presence of a disabled person and presence of a household member with a chronic illness were found to be consistently significant in all studies and regardless of the economic status of the country.

Hospitalisation (inpatient care) was identified as an important determinant as it consumes a high share of OOP payments made by households and leads to financial hardship $\left(12,15^{-17}, 19-22,26,33,35-39,48-50\right)$.

The presence of an elderly person in a household also significantly increases the probability of that household incurring CHE. This greater probability is associated with the greater need for, and utilisation of, healthcare services by the older generation compared to younger age groups (23). Although there is an increasing ageing population globally, the healthcare system in low- and middle-income countries still does not have sufficient resources to provide the necessary social safety net for the needs of this group. Similarly, the presence of a disabled person in the household increases the risk of experiencing CHE. A disabled person generally has a higher demand for health care, as identified by several studies. Also, health care for chronic illnesses was also found to be a significant determinant of financial hardship

Table 3. The role of the insurance in incurring CHE

\begin{tabular}{lll} 
Income category & Country & Insurance role \\
Middle & China (2010) & Significantly reduce CHE \\
Middle & Turkey (2010) & Significantly reduce CHE \\
Middle & Brazil (2011) & Risk factor \\
Middle & China (2011a) & Not significant \\
Middle & China (2011b) & Risk factor \\
Middle & Colombia (2011) & Significantly reduce CHE \\
Middle & China (2012) & Significantly reduce CHE \\
Middle & Iran (2012a) & Significantly reduce CHE \\
Middle & Iran (2012b) & Not significant \\
Middle & Vietnam (2013) & Significantly reduce CHE \\
Middle & Thailand (2013) & Not significant \\
Middle & China (2013) & Depends on the type of insurance scheme \\
Middle & West bank and Gaza (Palestine) (2O13) & Significantly reduce CHE \\
Middle & China (2014) & Depends on the type of insurance scheme \\
Middle & Turkey (2014a) & Significantly reduce CHE \\
Middle & Turkey (2014b) & Significantly reduce CHE \\
High & South Korea (2016) & Not significant \\
\hline
\end{tabular}


$(15,18-20,22,24,28,33,39,40,47,48,50)$. Responding to the healthcare demands of people with a chronic illness is a common challenge in many countries $(53,54)$. Moreover, the pandemic of non-communicable diseases (NCDs) has been a serious wake-up call for the healthcare systems of various countries. As many NCDs are chronic in nature and a major cause of mortality all over the world, there is an urgent need to identify evidence-based innovative strategies for the prevention and control of NCDs, and to strengthen healthcare systems to meet the higher healthcare costs of prolonged treatment. Thus, providing a safety net for vulnerable persons (the elderly, the disabled and those with a chronic illness) and the households of which they are part should be seriously considered as a crucial issue in financing health care and achieving UHC.

The majority of the selected studies used the same econometric models to assess the determinants of CHE. However, several studies used different methods and cut-off points to categorise the presence of CHE in households. Therefore, standardisation of both the method and measures used in studying this issue could enable a more relevant and useful comparison of the data across the globe.

Nevertheless, despite the methodological differences in reporting CHE in the various studies, some key points emerged from this review. Firstly, even in high-income countries, households still incur CHE (55). It is generally assumed that households in low-income countries have a higher risk of having CHE (8). However, the findings of this review contradict this assumption because the prevalence of CHE in low-income countries is not that much different from that in middle-income countries. It is possible that many people in low-income countries choose not to seek health care rather than face the financial hardship associated with healthcare payments. This supposition is supported by the findings reported in the studies on Burkina Faso and Iran, where households that utilise more health care are more likely to incur CHE $(18,36)$.

Secondly, most of the studies identified CHE based on household capacity to pay (15$22,24-27,29,33-40,44,47-50$ ), while a few studies used the ratio of OOP to total household income (12, 19, 23, 24, 26, 28, 34, 44, 46, 49). Thirdly, the studies that used both methods of calculation on the same sample population (19, $24,26,34,44,49)$ revealed that the prevalence of
CHE with regards to healthcare payments to total income was higher than the prevalence based on capacity to pay. However, there is no universally agreed cut-off point for calculating CHE, so researchers use a cut-off point of their own choosing, which limits comparability between studies. However, the most frequently used cutoff points are $10 \%$ of household income and $40 \%$ of household capacity to pay.

It is also necessary to reach a consensus on a single method of defining CHE (either based on income or capacity to pay). Hence, to validate these two methods, it would be useful to conduct further studies that define CHE by using both methods as in previous research conducted in Thailand (19), India (34) and Brazil (44). Furthermore, qualitative studies should be undertaken on households by using an in-depth interview approach to identify their perceived financial hardship and coping strategies. An analysis of the interviews would help to identify a method that is both sensitive and rational that can accurately capture the financial catastrophe experienced by households.

Thirdly, the role of insurance was found to vary among the included studies. In China, there are three government insurance schemes, the New Rural Cooperative Medical Scheme for rural residents and the Urban Employee Basic Medical Insurance Scheme and Urban Resident Basic Medical Insurance Scheme for urban residents (21). The prevalence of CHE was found to depend on the type of insurance scheme that the household had; the urban health insurance is protective while the rural one is a positive predictor that increases the risk of CHE. One study reported that enrolment in the rural insurance scheme had no effect on CHE prevalence among households when compared to those without insurance, and a possible explanation for this result is the limited coverage for outpatient, self-treatment and traditional medicine treatment (56).

The difference in the prevalence rate of CHE is not only related to the availability of health insurance, but also to the sampling used in the study design. For instance, in Thailand, the UHC policy consists of three major government schemes: the Civil Servant Medical Benefit Scheme, the Social Security Scheme, and the Universal Coverage Scheme, which provide comprehensive outpatient and inpatient coverage through somewhat different benefit packages (19). If the sample consists only of poor urban households, there is likely to be a 
high prevalence of CHE even under UHC. One possible explanation for the persistence of $\mathrm{CHE}$ among poor households in Thailand even after the implementation of the UHC may be due to the participants in the study seeking care from a facility at which they are not registered because care has to be accessed from facilities that operate under at least one of the three Schemes (19). However, Study in Zambia found reduction of CHE after implantation of user fees exemption policy (30).

Reconsideration and upgrading of the health insurance benefits package is crucial to reach a satisfactory level of financial risk protection. In Portugal for instance, although there is an exemption policy for children, the elderly and unemployed, that exemption does not cover the cost of pharmaceutical products and as such causes high OOP expenditure and financial burden (57). Likewise, in Uganda, the policy of charging users fees for health care was eliminated in 2001 in order to increase healthcare utilisation among the poor. However, the prevalence of CHE did not decrease because prescribed medicines were not made available at public hospitals and patients had to purchase them from private pharmacies (17).

In some low- and middle-income countries such as Bangladesh, Kenya, Tanzania, Myanmar and India, the healthcare financing system remains dependent on OOP expenditure. Such dependency reflects a less sustainable way of financing a healthcare system and as such is unable to guarantee any financial protection for vulnerable users of the healthcare system $(20,40)$. Similarly, Colombia and Turkey are facing issues in terms of the equity and quality of healthcare services, which ultimately jeopardises both of these countries' intentions of achieving UHC $(26,37)$. Also, in both the Czech Republic and Vietnam, the continuous budget deficit weakens the possibility of UHC continuing (23, 58).

In Iran, the existing comprehensive national insurance system requires an expansion of the benefit package and a decrease in the copayments to secure financial protection and avoid CHE (36). Similarly, in Georgia, both inpatient coverage and drug benefits need to be expanded (48). In Serbia, the health insurance fund does not fully cover all services required and the existence of high informal payments increases the risk of CHE (24).

In Brazil, private health insurance leads to a rise in the risk of CHE by increasing the demand for specialised and costly health services that further escalates the inequality of healthcare utilisation among the population (44). In Burkina Faso, although communitybased health insurance has been introduced, coverage remains limited and that's because it is a voluntary insurance, and there is currently zero possibility of achieving UHC (59). In South Korea, the moderate impact of insurance cover on financial protection shows that people with health insurance are still paying fairly high OOP payments (43). Lastly, in the USA, cost-sharing in Medicare and the high premium for insurance are more likely to expose low-income families to a greater risk of CHE (60).

The measurement of CHE has become increasingly important because it is one of the key parameters for financial protection in achieving UHC. However, this review discovered that there were some general weaknesses in the studies on CHE. For instance, the incidence of chronic illness is based on self-reported data rather than accurate medical diagnosis, which could lead to an over-estimation of the health expenditure on chronic illness. Moreover, payment for health care is solely based on the monetary value and the cost for institutional health care. Thus the methodology cannot capture the in-kind payments that are common in rural areas of low-income countries. Finally, CHE is estimated for households that decided to seek health care, but this does not capture the complete scenario because there are households that choose not to seek health care to avoid the financial hardship that would be incurred in making healthcare payments.

\section{Study Limitation}

For this review, papers published in languages other than English were excluded, so it is possible that some studies were missing. However, in the extensive search of databases only three papers published in non-English languages were found (and excluded). There are many non-English researches on CHE and these can be found in Google scholar. And several studies among them were in-depth studies analysed panel data. There is also a possibility that some studies which have been classified as 'grey literature' were missing and thus, there may be some risk of publication bias. However, this is not uncommon limitation for systematic review. 


\section{Conclusion}

The crucial finding of this study is that socioeconomic inequality plays an important role in the incidence of CHE all over the world, where low-income households are at high risk of financial hardship from healthcare payments and of falling below the poverty line as a consequence. The educational status and employment status of the head of household, need for healthcare to manage a chronic illness, and the presence of an elderly or disabled household member were also identified as predictors of CHE. Simultaneously, we would like to highlight that the representativeness of data and source of data and data collection system in different studies are different. Therefore the strength of the factors which effects catastrophic health expenditure and impoverishment may vary and may not be similar.

The findings of this review suggest that healthcare financing policies should be revised in order to narrow the gap in socioeconomic inequality and social safety nets should be implemented and strengthened for people who have a high need for health care such as the elderly, people with a chronic illness and disabled persons. Also, CHE can be used as an indicator for comparing fairness in the financing of health care across countries and within a country over a period of time. It can also be used to measure the level and effectiveness of financial protection, which is an important parameter of UHC.

\section{Acknowledgements}

None.

\section{Conflict of Interest}

None.

\section{Funds}

None.

\section{Authors' Contributions}

Conception and design: MA, TTS

Analysis and interpretation of the data: MA, TTS, AR

Drafting of the article: MA, TTS

Critical revision of the article for important intellectual content: MA, TTS, AR

Final approval of the article: MA, TTS, AR

Provision of study materials or patients: MA, TTS

\section{Correspondence}

Dr Meram Azzani

PhD (University of Malaya),

MBBS (University of Aden)

Community Medicine Department,

Faculty of Medicine \& Biomedical Sciences,

MAHSA University, Saujana Putra Campus, 42610 Jenjarom, Selangor, Malaysia.

Tel: +603 5102 2200/2759

E-mails: merammohammed@mahsa.edu.my, dr_memeazzani@yahoo.com

\section{References}

1. World Health Organization. The world health report 200O-Health systems: improving performance. Geneva: World Health Organization; 2000.

2. World Health Organization. The world health report 2010-Health systems financing: the path to universal coverage. Geneva: World Health Organization; 2010.

3. van Doorslaer E, O'Donnell O, Rannan-Eliya RP, Somanathan A, Adhikari SR, Akkazieva B, et al. Paying out-of-pocket for health care in Asia: catastrophic and poverty impact. EQUITAP project: Working paper no. 2; 2005.

4. Russell S. The economic burden of illness for households in developing countries: a review of studies focusing on malaria, tuberculosis, and human immunodeficiency virus/acquired immunodeficiency syndrome. Am $J$ of Trop Med and Hyg. 2004:71(Suppl 2):147-155. https://doi.org/10.4269/ajtmh.2004.71.147

5. Shahrawat R, Rao KD. Insured yet vulnerable: out-of-pocket payments and India's poor. Health Policy and Plan. 2012;27(3):213-221.

6. Thuan NTB, Lofgren C, Chuc NTK, Janlert U, Lindholm L. Household out-of-pocket payments for illness: evidence from Vietnam. BMC Public Health. 2006;6:283. https://doi.org/ 10.1186/1471-2458-6-283 
Review Article | Determinants of catastrophic health expenditure

7. Xu K, Evans DB, Carrin G, Aguilar-Rivera AM, Musgrove P, Evans T. Protecting households from catastrophic health spending. Health Aff. 2007;26(4):972-983. https://doi.org/10.1377/ hlthaff.26.4.972

8. Onoka CA, Onwujekwe OE, Hanson K, Uzochukwu BS. Examining catastrophic health expenditures at variable thresholds using household consumption expenditure diaries. Trop Med Int Health. 2011;16(10):1334-1341. https://doi: 10.1111/j.1365-3156.2011.02836.x

9. Ranson MK. Reduction of catastrophic health care expenditures by a community-based health insurance scheme in Gujarat, India: current experiences and challenges. Bull World Health Organ. 2002;80: 613-621.

10. Pradhan M, Prescott N. Social risk management options for medical care in Indonesia. Health Economics. 2002;11(5):431-446. https://doi.org/ 10.1002/hec.689

11. $\mathrm{Xu} \mathrm{K}$, Evans DB, Kawabata K, Zeramdini R, Klavus J, Murray CJL. Household catastrophic health expenditure: a multicountry analysis. The Lancet. 2003;362(9378):111-117. https://doi. org/10.1016/So140-6736(03)13861-5

12. Wyszewianski L. Families with catastrophic health care expenditures. Health Serv Res. 1987;21:5.

13. Center for Evidence Based Management. Critical appraisal. [Internet]. n.d. [Retrieved 2015 July 30]. Available from: http://www.cebma.org/ frequently-asked-questions/what-is-criticalappraisal/.

14. The World Bank. [Internet]. n.d. [Retrieved 2015 June 13]. Available from: http://data.worldbank. org/country.

15. Zhou Z, Gao J. Study of catastrophic health expenditure in China's basic health insurance. Health Med. 2011;5:1498.

16. Yardim S, Cilingiroglu N, Yardim N. Catastrophic health expenditure and impoverishment in Turkey. Health Policy. 2010;94:26-33. https:// doi.org/10.1016/j.healthpol.2009.08.006

17. Xu K, Evans DB, Kadama P, Nabyonga J, Ogwal PO, Nabukhonzo P, et al. Understanding the impact of eliminating user fees: utilization and catastrophic health expenditures in Uganda. Soc Sci Med. 2006;62(4):866-876. https://doi. org/10.1016/j.socscimed.2005.07.004
18. Su TT, Kouyate B, Flessa S. Catastrophic household expenditure for health care in a lowincome society: a study from Nouna District, Burkina Faso. BullWorld Health Organ. 2006;84:21-27.

19. Somkotra T, Lagrada LP. Which households are at risk of catastrophic health spending: experience In Thailand after universal coverage. Health Aff. 2009;28:467-478. https://doi.org/10.1377/hlthaff. 28.3.w467

20. Mondal S, Kanjilal B, Peters DH, Lucas H. Catastrophic out-of-pocket payment for health care and its impact on households: experience from West Bengal, India. Baltimore, MD: Future Health Systems; 2010. Available from: http:// www.chronicpoverty.org/uploads/publication_ files/mondal_et_al_health.pdf

21. Li Y, Wu Q, Xu L, Legge D, Hao Y, Gao L, et al. Factors affecting catastrophic health expenditure and impoverishment from medical expenses in China: policy implications of universal health insurance. Bull World Health Organ. 2012:90:664-671. https://doi.org/10.2471/BLT. 12.102178

22. Li X, Shen JJ, Lu J, Wang Y, Sun M, Li C, et al. Household catastrophic medical expenses in eastern China: determinants and policy implications. BMC Health Serv Res. 2013;13:506. https://doi.org/10.1186/1472-6963-13-506

23. Krutilova V, Yaya S. Unexpected impact of changes in out-of-pocket payments for health care on Czech household budgets. Health Policy. 2012;107:276-288. https://doi.org/10.1016/j. healthpol.2012.07.002

24. Arsenijevic J, Milena Pavlova, Wim Groot. Measuring the catastrophic and impoverishing effect of household health care spending in Serbia. Soc Sci Med. 2013;78:17-25. https://doi. org/10.1016/j.socscimed.2012.11.014

25. Minh HV, Phuong NTK, Saksena P, James CD, Xu K. Financial burden of household out-of pocket health expenditure in Viet Nam: findings from the National Living Standard Survey 2002-2010. Soc Sci Med. 2013;96:258-263. https://doi. org/10.1016/j.socscimed.2012.11.028 
26. Özgen Narcı H, Sahin I, Yildirim HH. Financial catastrophe and poverty impacts of out-of-pocket health payments in Turkey. Eur $J$ Health Econ. 2015;16(3):255-270. https://doi.org/10.1007/ S10198-014-0570-Z

27. Kronenberg C, Barros PP. Catastrophic healthcare expenditure - Drivers and protection: The Portuguese case. Health Policy. 2014;115(1):44-51. https://doi.org/10.1016/j. healthpol.2013.10.001

28. Brown S, Hole AR, Kilic D. Out-of-pocket health care expenditure in Turkey: analysis of the 2003-2008 household budget surveys. Economic Modelling. 2014;41:211-218. https://doi.org/ 10.1016/j.econmod.2014.05.012

29. Ashour M, Abuzaid A, Korachais C. Catastrophic health expenditure and entitlement to health services in the occupied Palestinian territory: a retrospective analysis. The Lancet. 2013;382(Suppl 1):3. https://doi.org/10.1016/ So140-6736(13)62164-9

30. Masiye F, Kaonga O, Kirigia JM. Does user fee removal policy provide financial protection from catastrophic health care payments? Evidence from Zambia. PLoS ONE. 2016;11(1):e0146508. https://doi.org/10.1371/journal.pone.0146508

31. Khaing IK, Malik A, Oo M, Hamajima N. Health care expenditure of households in Magway, Myanmar. Nagoya $J$ Med Sci. 2015;77(12):203-212.

32. Htet S, Fan V, Alam K, Mahal A. Financial risks from ill health in Myanmar: evidence and policy implications. Asia Pac $J$ Public Health. 2015;27(4):418-428. https://doi.org/ 10.1177/1010539514558332

33. Shi W, Chongsuvivatwong V, Geater A, Zhang J. Effect of household and village characteristics on financial catastrophe and impoverishment due to health care spending in Western and Central Rural China: a multilevel analysis. Health Res Policy Syst. 2011;9:16. https://doi. org/10.1186/1478-4505-9-16

34. Pal R. Measuring incidence of catastrophic outof-pocket health expenditure: with application to India. Int $J$ Health Care Finance Econ. 2012;12:63-85. https://doi.org/10.1007/s10754012-9103-4
35. Moghadam MN, Banshi M, Javar MA, Amiresmaili M, Ganjavi S. Iranian household financial protection against catastrophic health care expenditures. Iranian $J$ Public Health. 2012;41(9):62-70.

36. Kavosi Z, Rashidian A, Pourreza A, Majdzadeh R, Pourmalek F, Hosseinpour AR, et al. Inequality in household catastrophic health care expenditure in a low-income society of Iran. Health Policy Plan. 2012;27:613-623. https://doi.org/10.1093/ heapol/czsoo1

37. Amaya JL, Ruiz GF. Determining factors of catastrophic health spending in Bogota, Colombia. Int $J$ Health Care Finance Econ. 2011;11:83-100. https://doi.org/10.1007/s10754-011-9089-3

38. Misra S, Awasthi S, Sing JV, Agarwal M, Kumar V. Assessing the magnitude, distribution and determinants of catastrophic health expenditure in urban Lucknow, North India. Clinical Epidemiology and Global Health. 2013;3(1):1-7. https://doi.org/10.1016/j.cegh.2013.10.003

39. Li Y, Wu Q, Lie C, Kang Z, Xie X, Yin H, et al. Catastrophic health expenditure and rural household impoverishment in China: what role does the new cooperative health insurance scheme play? PLoS ONE. 2014;9(4):e93253. https://doi.org/10.1371/journal.pone.0093253

40. Mary BE, Antonio AR, Enemark Ulrika E. Correlates of out-of-pocket and catastrophic health expenditures in Tanzania: results from a national household survey. BMC Int Health and Hum Rights. 2014;14:5. https://doi. org/10.1186/1472-698X-14-5

41. Bakhtiar Piroozi, Moradi G, Nouri B, Bolbanabad AM, Safari H. Catastrophic health expenditure after the implementation of health sector evolution plan: a case study in the West of Iran. IJHPM. 2016;5(7):417--423. https://doi.org/ 10.15171/IJHPM.2016.31

42. Xu Y, Gao J, Zhou Z, Xue Q, Yang J, Luo H, et al. Measurement and explanation of socioeconomic inequality in catastrophic health care expenditure: evidence from the rural areas of Shaanxi Province. BMC Health Serv Res. 2015;15:256. https://doi. org/10.1186/s12913-015-0892-2 
Review Article | Determinants of catastrophic health expenditure

43. Choi JW, Kim TH, Jang SI, Jang SY, Kim W-R, Park EC. Catastrophic health expenditure according to employment status in South Korea: a population-based panel study. BMJ Open. 2016;6(7):eo11747. http://dx.doi.org/10.1136/ bmjopen-2016-011747

44. Aluísio B, João B, Andréa D. Catastrophic spending on health care in Brazil: private health insurance does not seem to be the solution. Cad Saúde Pública. 2011;27:254-262. http://dx.doi. org/10.1590/So102-311X2011001400012

45. Buigut S, Ettarh R, Amendah DD. Catastrophic health expenditure and its determinants in Kenya slum communities. Int $J$ Equity Health. 2015;14:46. https://doi.org/10.1186/s12939-0150168-9

46. Weraphong J, Pannarunothai S, Luxananun T, Junsri N, Deesawatsripetch S. Catastrophic health expenditure in an urban city: seven years after universal coverage policy in Thailand. Southeast Asian J Trop Med Public Health. 2013;44(1):124-136.

47. Shi W, Chongsuvivatwong V, Geater A, Zhang J, Zhang H, Brombal D. The influence of the rural health security schemes on health utilization and household impoverishment in rural China: data from a household survey of western and central China. Int J Equity Health. 2010;9:7. https://doi. org/10.1186/1475-9276-9-7

48. Gotsadze G, Zoidze A, Rukhadze N. Household catastrophic health expenditure: evidence from Georgia and its policy implications. $B M C$ Health Serv Res. 2009:9:69. https://doi.org/ 10.1186/1472-6963-9-69

49. Chuma J, Maina T. Catastrophic health care spending and impoverishment in Kenya. BMC Health Serv Res. 2012;12:413. https://doi.org/ 10.1186/1472-6963-12-413

50. Rahman MM, Gilmour S, Saito E, Sultana P, Shibuya K. Health-related financial catastrophe, inequality and chronic illness in Bangladesh. PloS ONE. 2013:8(2):e56873. https://doi.org/10.1371/ journal.pone.0056873

51. Boing AC, Bertoldi AD, de Barros AJD, Posenato LG, Peres KG. Socioeconomic inequality in catastrophic health expenditure in Brazil. Rev Saude Publica. 2014;48(4):632-641. https://doi. org/10.1590/Soo34-8910.2014048005111
52. Sun X, Jackson S, Carmichael G, Sleigh AC. Catastrophic medical payment and financial protection in rural China: evidence from the New Cooperative Medical Scheme in Shandong Province. Health Econ. 2008:18:103-119. https://doi.org/10.1002/hec.1346

53. Islam MM, Yen L, Valderas JM, McRae IS. Outof-pocket expenditure by Australian seniors with chronic disease: the effect of specific diseases and morbidity clusters. BMC Public Health. 2014;14:1008. https://doi.org/10.1186/14712458-14-1008

54. Bhojani U, Thriveni BS, Devadasan R, Munegowda CM, Devadasan N, Kolsteren P, et al. Out-of-pocket healthcare payments on chronic conditions impoverish urban poor in Bangalore, India. BMC Public Health. 2012;12:990. https:// doi.org/10.1186/1471-2458-12-990

55. Chowdhury S. Financial burden of transient morbidity: a case study of slums in Delhi. Econ Polit Wkly. 2011;46:59-66.

56. Peters DH, Garg A, Bloom G, Walker DG, Brieger WR, Rahman AH. Poverty and access to health care in developing countries. Ann NY Acad Sci. 2008:1136(1):161-171. https://doi.org/10.1196/ annals.1425.011

57. Rodrigues R, Schulmann K. Impacts of the crisis on access to healthcare services: country report on Portugal. Dublin: Eurofound; 2014.

58. Somanathan A, Dao HL, Tien TV. UNICO Studies Series 24: integrating the poor into universal health coverage in Vietnam. Hanoi, Vietnam: Ministry of Health; 2013.

59. World Health Organization. WHO country cooperation strategies and briefs. Geneva, Switzerland: World Health Organization. Available from: http://www.who.int/ countryfocus/cooperation_strategy/ccsbrief_bfa_ en.pdf

60. Briesacher BA, Ross-Degnan D, Wagner AK, Fouayzi H, Zhang F, Gurwitz JH, et al. Out-ofpocket burden of health care spending and the adequacy of the medicare part $d$ low-income subsidy. Med Care. 2010;48(6):503-509. https://doi.org/10.1097/MLR.obo13e3181dbd8d3 